\title{
Programme
}

WEDNESDAY - February 1, 2006

$10.00-10.10$

Welcome, by Claus H. Andersen, Consortium Manager, PBD

$10.10-10.45$

Session 1 - Plant Products and Plant Productivity

(chair: Preben Bach Holm)

Dietary Bioactives: Engineering Secondary metabolism in Plants

for Improved Foods, by Cathie Martin, Professor in Plant Biology, The John Innes Centre, UK

$10.45-11.15$

Coffee

$11.15-11.35$

$11.35-11.55$

$11.55-12.15$

Engineering the glucosinolate pathway into potato, by Fernando Geu Flores, Department of Plant Biology, KVL

Elucidating part of the phytic acid biosynthetic pathway in plants, by Lone Josefsen, Ph D student, Department of Agricultural Sciences, KVL

Transcription of nuclear encoded Photosystem I genes in Arabidopsis mutants lacking PSI-D and PSI-F mutants differs although the mutants have similar phenotypes, by Anna Haldrup, Head of Department, Department of Plant Biology, KVL

$12.15-12.35$

Why do plants contain the blood molecule haemoglobin?, by Kim $\mathrm{H}$. Hebelstrup, PhD student, Department of Molecular Biology, University of Århus University

$12.35-13.35 \quad$ Lunch in the Marble Hall

Session 2 - Plant Nutrition and Plant Disease (chair: Jan K. Schjørring)

$13.35-14.10$

Defensive models, by John Mundy, Professor, Institute of Molecular Biology and Physiology, University of Copenhagen

$14.10-14.30$

New insights into the function of aquaporins in solute transport and signalling, by Thomas P. Jahn, Associate Professor, Department of Agricultural Sciences, KVL

$14.30-14.50$

Analysis of the ferritin family in Lotus japonicus, by Winnie Jensen, M Sc student, Department of Molecular Biology, University of Århus

$14.50-15.15 \quad$ Coffee

$15.15-15.35$

$15.35-15.55$

NAC Transcription Factors as Regulators of Plant Defence Responses, by Michael K. Jensen, PhD student, Department of Plant Biology, KVL

Novel Arabidopsis mutant activated in a number of defence pathways, by Ziguo Zhang, Senior Scientist, Department of Agricultural Sciences, KVL

Poster Session in the Marble Hall 

THURSDAY - February 2, 2006

$09.00-09.35$

Session 3 - Plant Breeding and Systems Biology

(chair: Sven Bode Andersen)

Cell Separation processes in plants: systems, signals and selection, by Jeremy Alan Roberts, Professor in Plant Biology, University of Nottingham, UK

$09.35-9.55$

Vernalization response in perennial ryegrass (Lolium perenne L.) involves orthologues of diploid wheat (Triticum monococcum)

VRN1 and rice (Oryza sativa) Hd1, by Jeppe Reitan Andersen, Project Scientist, Department of Genetics and Biotechnology, DIAS

$9.55-10.15$

Transformation of barley (Hordeum vulgare L.) by Agrobacterium tumefaciens infection of in vitro cultured ovules, by Inger Bæksted Holme, Project Senior Scientist, Department of Genetics and Biotechnology, DIAS

$10.15-10.45$

Coffee

$10.45-11.05$

Proteome analysis of the barley aleurone layer: a model system for plant signalling, by Christine Finnie, Research Associate Professor, BioCentrum, DTU

Full-cDNA, SAGE and proteome analyses of potato tuber. Striking sequence variations among cultivars, by Karen G. Welinder,

Professor, Department of Biotechnology, Chemistry and Environmental Engineering, Aalborg University

$11.25-12.00$

Perspectives in using plants for production of GMO Foods and Food ingredients, by Jørn Dalgård Mikkelsen, Director, Danisco A/S

$12.00-13.00 \quad$ Lunch

$13.00-15.00$

Work Shop - Organizer and contact Søren K. Rasmussen (skr@kvl.dk)

- The European Triticeae Genomics Initiative (ETGI) from a Danish perspective

- Reports from the Plant and Animal Genome Conference, PAG-XIV

- Genomics on other grasses (Lollium and Brachypodium) 



\section{Abstracts selected for presentation}




\section{Abstracts Selected for Presentation}

\section{Products}

\section{Engineering the glucosinolate pathway into potato}

Fernando Geu Flores ${ }^{1}$, Barbara Ann Halkier ${ }^{1}$, Marc Ghislain ${ }^{2}$ and Eric Cosio ${ }^{3}$

${ }^{1}$ Plant Biochemistry Laboratory and Center for Molecular Plant Physiology (PlaCe), Institute for Plant Biology, The Royal Veterinary and Agricultural University (KVL), Copenhagen, Denmark ${ }^{2}$ International Potato Center, Lima, Peru

${ }^{3}$ Ponthifical Catholic University of Peru, Lima, Peru

Glucosinolates are amino acid-derived secondary metabolites present in the agriculturally important Brassica vegetables, such as e.g. oilseed rape and broccoli. Their bioactivity ranges from functioning as feeding attractants/deterrents for herbivores to conferring specific pest resistance to crops. They are known to humans for their cancer-preventive properties, their characteristic mustard flavour, and their use as biopesticides. The synthesis of the core structure of glucosinolates involves at least 5 different gene products, probably assembled as a metabolon complex. With the recent identification of the C-S lyase, the S-glucosyltransferase, and the sulfotransferase (1,2 and 3), and the previously known cytochromes CYP79 and CYP83, transfer of the glucosinolate pathway to heterologous hosts has become a realistic goal. We have initiated efforts to engineer the whole pathway into potato, in order to confer resistance to the late blight disease and the brown rot. Since the traditional transgene stacking is not convenient (considering the number of genes involved), an alternative method has been adopted. This method utilizes virus-derived sequences as part of one-ORF multicistronic constructs, which allow the expression of several genes from a single promoter sequence (4).

References:
(1)
Mikkelsen et al. (2004) Plant J 37(5), 770-777
(2)
Douglas Grubb et al. (2004) Plant J 40(6), 893-908
(3)
Piotrowski et al. (2004) J Biol Chem 279 (49), 50717-50725
(4)
El Amrani et al. (2004) Plant Physiol 135(1), 16-24 


\section{Abstracts Selected for Presentation}

\section{Products}

\section{Elucidating part of the phytic acid biosynthetic pathway}

Lone Josefsen, Kirsten Bagge Holm and Søren K. Rasmussen

Department of Agricultural Sciences, KVL

Phytic acid is a major storage compound in plant seeds. It stores up to $80 \%$ of the total seed phosphorous and contributes up to $1,5 \%$ of the seed dry weight. The negatively charged phosphates in phytic acid strongly bind to metallic cations (e.g. Ca, Fe, K, Mg, Mn and Zn) and form a mixed salt called phytate. During the past years there has been focus on phytic acid as an anti-nutrient in the diets of non- ruminants because of their inability to utilize phytate. Excretion of dietary phytic acid as a salt of nutritionally important mineral cations can lead to both $\mathrm{P}$ and mineral deficiencies in human populations where staples as wheat, rice and maize is the major or only source of daily food intake.

So far only a few genes active in the synthesis of phytic acid in plants have been identified. Here we present two genes coding for proteins with inositol phosphate kinase activity from rice and barley, respectively. The recombinant proteins show kinase activity towards several inositol phosphate substrates, thus indicating that the genes have multiple roles in the biosynthetic pathway in plants. Expression analysis has shown that the two genes are expressed in most plant tissues which lead to a discussion of their role in deposition of phytate during seed development. 


\section{Abstracts Selected for Presentation}

\section{Productivity}

\section{Transcription of nuclear encoded Photosystem I genes in Arabidopsis mutants lacking PSI-D and PSI-F mutants differs although the mutants have similar phenotypes}

Anna Haldrup, Kasper Jensen Busk, Anastassia Khrouchtchova, Dario Leister, Stefan Jansson, Lone Baunsgaard, and Henrik Vibe Scheller

AH, KJB, LB, AK, HVS: Plant Biochemistry Laboratory, Department of Plant Biology, The Royal Veterinary and Agricultural University, 40 Thorvaldsensvej, DK-1871 Frederiksberg C,

Copenhagen, Denmark

DL: Abteilung für Pflanzensüchtung und Ertragsphysiologie, Max-Planck-Institu für

Züchtungsforschung, Carl von Linné Weg 10, 50829 Köln, Germany (D.L.)

SJ: Umeå Plant Science Center, Department of Plant Physiology, University of Umeå, 90187

Umeå, Sweden

Photosynthesis is partly regulated by environmental factors such as light and partly by the state of the photosystem itself such as redox state. Plants with low amount of PSI-F up-regulate nuclear encoded PSI genes whereas plants low in PSI-D down-regulate the nuclear encoded genes. The mutants therefore exhibit a perfect tool for studying regulatory mechanisms in plants. Both mutants have an over-reduced plastoquinone pool, a less reduced stroma, and a high phosphorylation level of LHCII and both up-regulate the xanthophyll. Both mutants grow very slowly and become lightstressed even in low light at normal temperature and up-regulate VDE, PsbS, NDH-I, Fd, FNR and cytochrome f. ROS are known to activate the expression of both the chloroplast and nuclear genes including antioxidants, but both mutants produce high amounts of $\mathrm{H} 2 \mathrm{O} 2$ and super oxide during normal growth. Sugars can act as regulatory factors but both mutants produce very low amounts of sucrose, glucose and fructose. Besides the difference in PSI gene regulation, plants reduced in PSI-F up-regulate the amount of LHCII protein whereas plants reduced in PSI-D down-regulate the amount of LHCII protein.

Arabidopsis plants down-regulated in PSI-F are affected in electron transport due to a weaker binding of plastocyanin (PC) (Haldrup et al. 2000) and plants with low amounts of PSI-D are in fact PSI deficient plants, suggesting that PSI-D is important for assembly of PSI in plants (Haldrup et al. 2003). 


\section{Abstracts Selected for Presentation}

\section{Productivity}

\section{Why do plants contain the blood molecule haemoglobin?}

Kim H. Hebelstrup, Erik Ø. Jensen

Molekylærbiologisk Institut, Aarhus Universitet, Gustav Wieds Vej 10C, 8000 Aarhus C, e-mail: khh@mb.au.dk

It is well-known that haemoglobin play an important role in the transport of oxygen from lungs or gills to muscles, brain and other oxygen-consuming organs. But haemoglobin is also found inside the cells of many organisms without blood. It is found even in uni-cellular organisms such as bacteria. And it is found in plants. It has been known for long that some plant species - such as the legumes - can form symbiotic root nodules with nitrogen-fixing bacteria and that these nodules contain (leg)haemoglobin, which bind and facilitate diffusion of oxygen. However, haemoglobin has been identified in other plant organs and in several plant families, not forming symbiotic nodules at all. This project presents data suggesting that plant haemoglobin play an essential role in all plants, a role different from oxygen transport. Plant haemoglobin rather works as an enzyme that scavenges the small signalling molecule nitric oxide (NO). By a series of experiments with haemoglobin gene promoter reporter, silencing- and over-expression lines of Arabidopsis thaliana, we have been able to show that the interaction of plant haemoglobin with NO in Arabidopsis is controlling important processes such as growth, organ development, bolting and adaptation to hypoxia. This suggests that plant haemoglobin is far from being a symbiotic nodule specific factor as it was originally thought to be. 


\section{Abstracts Selected for Presentation}

\section{Nutrition}

\section{New insights into the function of aquaporins in solute transport and signalling}

Thomas P. Jahn, Anders L.B. Møller, Gerd P. Bienert, Floor ten Hoopen, Désirée Schussler, Pia Nord-Larsen, Josefine N Hegelund and Jan K. Schjørring

Plant and Soil Science Laboratory, Department of Agricultural Sciences, The Royal Veterinary and Agricultural University, Thorvaldsensvej 40, 1871 Frederiksberg C

Solute and ion transport across biological membranes is regulated by specific transporters in the membranes, some of which actively transport solutes against their concentration gradients. Water transport is secondarily coupled to the solute transport by osmosis and the diffusion of water across the lipid bilayer of membranes is facilitated by aquaporins, a large family known as diffusion facilitators called major intrinsic proteins (MIPs). The observation, that water diffusion across membranes is facilitated by protein channels has attracted broad interest in biology and medicine. More recently, it became evident, that in addition to water, many aquaporins also transport other compounds such as urea, ammonia, carbon dioxide and various polyols. In fact, glycerol was the first substrate identified for a major intrinsic protein. While water appears to be a common substrate to most isoforms, other substrates are restricted to a rather limited group. We have now obtained evidence, that even hydrogen peroxide passes some aquaporins, extending the list of substrates into the functional group of signalling molecules. Strikingly, the concentrations of these substrates in biological systems are usually found several orders of magnitude below that of water. Thus, it appears that members of the MIP family transport both solvent and solute molecules. This dual function may indicate a more complex molecular role of aquaporins in membrane transport and allows new speculations. One such speculation is that the diversity of aquaporins has developed to transport other substrates than water, and that water transport is needed to balance osmotic gradients that naturally develop in the course of solute transport. In any case, the increasing number of substrates clearly shows that there is more than water to the large family of aquaporins. 


\section{Abstracts Selected for Presentation}

\section{Nutrition}

\section{Analysis of the ferritin family in Lotus japonicus}

Winnie Jensen, Christina Cvitanich and Erik Østergaard Jensen. Laboratory of Gene Expression, Department of Molecular Biology, University of Aarhus.

Iron deficiency is a major global nutritional problem, where most of the affected people live in poor areas. Iron supplementation is the most common treatment, but due to economy it cannot be used to prevent iron deficiency.

Ferritins are iron storage proteins, that will bind excess iron in the cells, having a function in iron storage and in protecting the cells from harmful effects of free iron. Ferritins can be overexpressed resulting in plants containing increased amounts of iron. Furthermore, ferritin iron is biological available to humans. Plants containing higher levels of iron could be the solution to the iron deficiency problem in the undeveloped part of the world.

Searching Lotus japonicus sequence databases we have identified four ferritins, named ferritin 1 , 2, 3 and 4. Full length cDNA sequences are available for three of them, but genomic sequence is available only for ferritin 1 and 4 . L. japonicus ferritins are highly conserved compared to other plant ferritins.

Southern blot analysis also indicates the presence of four ferritin genes. This is in good agreement with the size of other plant ferritin families, e.g. the Arabidopsis and cowpea families, which both contain four members.

Expression of ferritin genes in response to iron overload was quantified using Real Time RT-PCR. Ferritin 1 is induced in the leaves by iron treatment while ferritin 2 and 3 show no induction in the leaves.

RNA has been extracted from different tissues of $L$. japonicus plants that were treated with iron, and the expression pattern of each ferritin in individual tissues will be studied. 


\section{Abstracts Selected for Presentation}

\section{Diseases}

\section{NAC Transcription Factors as Regulators of Plant Defence Responses}

Michael K. Jensen ${ }^{1}$, Torben Gjetting ${ }^{2}$, Peter Hagedorn ${ }^{2}$, Michael Lyngkjær ${ }^{2}$, Sisse Gjetting ${ }^{1}$, Jesper H. Rung ${ }^{1}$ and David B. Collinge ${ }^{1}$

${ }^{1}$ Royal Veterinary and Agricultural University (RVAU), Thorvaldsensvej 40, DK-1871 Frederiksberg

C, Denmark

${ }^{2}$ Risoe National Laboratory, 4000 Roskilde, Denmark

Corresponding author: mkrj@kvl.dk

NAC proteins constitute a large family of plant-specific transcription factors. They are believed to be involved in the floral and lateral root development in Arabidopsis thaliana (Aida et al, 1999; Xie et al, 2000). NAC transcripts have furthermore been shown to be upregulated by different abiotic and biotic stresses, including pathogen attacks and abscisic acid treatment (Hegedus et al, 2003, Greve et al, 2003). Furthermore yeast two-hybrid analyses have revealed the interaction between a viral capsid protein and an A. thaliana NAC member (Ren et al, 2000).

Colleagues at Section for Plant Pathology at KVL have isolated a NAC transcript from barley by differential display of powdery mildew-infected barley epidermis, 72 hai, and obtained the full length cDNA by RACE PCR. The clone was named HvNAC6 $(H$. vulgare) for its high sequence identity to the rice NAC protein OsNAC6 (O. sativa). HvNAC6 was used as bait to screen a cDNA library for other HvNACs, and three additional full length clones were obtained, representing three other NAC subfamilies.

Our group is currently working on the biological and biochemical function of these transcription factors. The biological functions of HVNAC genes are studied by the use of a transient expression assay in detached barley leaves. In this assay RNA interference (RNAi) and over-expression is used to determine the role of HVNAC6 upon powdery mildew inoculation. Quantitative RT-PCR has revealed a putative down-regulation of HVNAC6 transcripts upon powdery mildew infection. The biochemical function of the HVNAC gene products will be analysed by yeast two-hybrid analyses, gel overlay assays and immunoprecipitation. Hence, the aim of the current research is to delineate the signalling pathway involving this family of transcription factors and their function in the mediation of defence responses and/or suppression of plant defence responses toward pathogens. 


\section{Abstracts Selected for Presentation}

\section{Diseases}

\section{Novel arabidopsis mutant activated in a number of defence pathways}

Ziguo Zhang, Jin-Long Qiu, Carsten Petersen, Mari-Anne Newman, Angela Feechan \& Hans Thordal-Christensen

Dept. of Agricultural Sciences, The Royal Veterinary and Agricultural University, Thorvaldsensvej 40, 1871 Frederiksberg C, Copenhagen, Denmark

Plants actively defend themselves against pathogen attack using a number of defence pathways, which leads to manifestation of a battery of defence mechanisms combating the invaders. These pathways are silent in normal, unstressed plants, and they become activated upon attack if the plant is able to recognize the pathogen.

In Arabidopsis, we have identified a mutant which has constitutive activation of a number of defence pathways. However, since the resulting defence mechanisms are damaging, the plants are dwarfed and necrotic. One of these defences is mediated by salicylic acid (SA). This was studied by introducing mutations in the SA-pathway genes, EDS1, SID2, EDS5 and NPR1, and by introducing the transgene NahG, encoding a SA hydrolase converting SA to catechol. This partially rescues the plant and tell us that our mutant is knocked out in an upstream negative regulators of the SA-mediated defence response.

Data will be presented, which demonstrate that also the jasmonic acid (JA) and ethylene (ET)pathways are activated, and that disease resistant plants can be generated by combining several mutants in defence pathways. 


\title{
Abstracts Selected for Presentation
}

Breeding

\section{Vernalization response in perennial ryegrass (Lolium perenne L.) involves orthologues of diploid wheat (Triticum monococcum) VRN1 and rice (Oryza sativa) Hd1}

\author{
Jeppe Reitan Andersen, Louise Bach Jensen, Torben Asp and Thomas Lübberstedt \\ Danish Institute of Agricultural Sciences, Research Centre Flakkebjerg, 4200 Slagelse
}

Flowering time is important when adapting crop plants to different environments. While high feeding quality of forage grasses is facilitated by repression of flowering, flowering should also be inducible to facilitate grass seed production. Consequently, the identification and characterization of the genes controlling flowering time in forage grasses, including perennial ryegrass (Lolium perenne L.), is of great interest. In this study, three candidate genes for vernalization response genes in perennial ryegrass were identified based on DNA sequence homology to TmVRN1 and TmVRN2 of diploid wheat (Triticum monococcum), and Hd1 of rice (Oryza sativa). High sequence similarity between LpVRN1 and TmVRN1, co-localization of LpVRN1 with a major quantitative trait loci (QTL) for vernalization response in perennial ryegrass, synteny between map-positions of LpVRN1 and TmVRN1, mRNA expression analysis of LpVRN1 alleles during vernalization, and the correspondence between LpVRN1 mRNA expression levels and flowering time leads us to conclude that LpVRN1 is orthologous to TmVRN1 and that its function is conserved between diploid wheat and perennial ryegrass. Of the remaining two candidate genes, a putative Hd1 orthologue, LpCO, co-localized with a second QTL for vernalization response. LpCO has recently been shown to be involved in the photoperiodic regulation of flowering time. While epistasis, at the level of LpVRN1 transcription, was observed between the LpVRN1 and LpCO genomic regions, no differential expression of $\mathrm{LPCO}$ transcripts was observed during vernalization. While orthologous genes controlling flowering time can thus be identified, future allele sequencing efforts will reveal if causative polymorphisms are conserved across the grasses. 


\section{Abstracts Selected for Presentation}

\section{Breeding}

\section{Transformation of barley (Hordeum vulgare L.) by Agrobacterium tumefaciens infection of in vitro cultured ovules}

Inger Bæksted Holme, Henrik Brinch-Pedersen, Mette Lange and Preben Bach Holm

Danish Institute of Agricultural Sciences, Department of Genetics and Biotechnology, Research Centre Flakkebjerg, DK-4200 Slagelse, Denmark

We report on the successful transformation of barley by Agrobacterium infection of in vitro cultured ovules isolated within a few hours after pollination. As a first step we confirmed that the ovule culture technique allows for a highly efficient regeneration of green, phenotypic normal and fully fertile plants from zygotes and furthermore that the ovule culture system appears to be largely independent of genotype. For the transformation experiments ovules of the cultivar Golden Promise were isolated shortly after fertilization and infected with an Agrobacterium strain that carried the binary vector pVec8-GFP containing a hygromycin resistance gene and the green fluorescence protein (GFP) gene. Infected ovules were cultured in vitro under non-selective conditions or under hygromycin selection. GFP-expressing embryos were isolated from the ovules and regenerated to plants. The transformation frequency from a sample of 389 ovules cultured without selection amounted to $0.8 \%$ while hygromycin selection on 519 ovules resulted in transformation frequencies of 3.1\%. Mendelian inheritance of the GFP gene was confirmed by fluorescence analyses of GFP-expression in pollen and embryos in eighteen plants over two generations. Southern blotting revealed that most plants contained one to two GFP-gene inserts while a few plants possessed up to four inserts. We conclude that the described technique allows for the generation of non-chimeric transgenic plants without using selection, that the transformation frequency when implementing selection is comparable to that obtained by other Agrobacterium mediated techniques in barley and finally that the ovule regeneration technique is independent of genotype. 


\section{Abstracts Selected for Presentation}

Systems Biology

\section{Proteome analysis of the barley aleurone layer: a model system for plant signalling}

Christine Finnie, Radovan Hynek, Vibeke Barkholt and Birte Svensson

Biochemistry and Nutrition Group, BioCentrum-DTU, Building 224, Technical University of Denmark, 2800 Kgs. Lyngby, Denmark.

The aleurone layer of cereal seeds plays a key role in germination, responding to a gibberellic acid signal by synthesizing hydrolytic enzymes that are released to the endosperm. The barley aleurone layer can be separated from the other seed tissues and maintained in culture, allowing study of the effect of added signalling molecules in an isolated system. These properties have led to its use as a model system for the study of plant signalling and germination. Germination-related changes in response to gibberellic acid have been analysed in the proteomes of isolated aleurone layers maintained in culture using one and two-dimensional gel electrophoresis and mass spectrometry. Membrane proteins have been isolated in addition to the soluble proteins as they are likely to have key roles in germination signalling. The experimental system also enables analysis of the release of hydrolytic enzymes since these accumulate in the medium. This is an important function of the aleurone layer that is difficult to analyse in intact seeds. Released proteins in over 80 spots have been identified on the 2D-gels, including proteins involved in hydrolysis of starch, beta-glucan, arabinoxylan, fructan and proteins. Despite the fact that much is known about the proteins synthesized by aleurone layers, this approach has also led to identification of new proteins with unknown functions. 


\section{Abstracts Selected for Presentation}

\section{Systems Biology}

\section{Full-cDNA, SAGE and proteome analyses of potato tuber. Striking sequence variations among cultivars}

Karen G. Welinder, Heidi V. Nielsen, Guy Bauw, Malene Jensen*, Simon Hald, Allan Stensballe, Jeppe Emmersen, Annabeth Høgh Laursen, Kåre Lehmann Nielsen,

Department of Biotechnology, Aalborg University, Sohngaardsholmsvej 49, DK-9000 Aalborg, and *AKV-Langholt, Dragsholtvej 92, DK9310-Vodskov, and Andreas Blennow, The Royal Veterinary and Agricultural University, Thorvaldsensvej 40, 1871 Frederiksberg C, Denmark.

This century will witness an explosion in the fundamental knowledge of crops derived from genome, transcriptome, proteome and metabolome studies. The challenge will be to translate this knowledge into healthier plants and innovative products. A road map for coordinated large-scale research on Solanaceae species was drafted last year (http://sgn.cornell.edu/solanaceae-project/) although a number of potato and tomato projects have already produced ca. 190.000 ESTs for each of these crops. We have first concentrated on gene discovery by EST, SAGE and proteome studies of potato tuber. The industrial starch potato cultivar Kuras was chosen as a model, because this cultivar is presently the most important in Northern Europe due to a high starch yield and good pest resistance. The results include 500 full-cDNA sequences almost doubling the potato full-cDNAs in GenBank, a comprehensive comparison of gene transcription during tuber development, and the proteomes of potato juice, amyloplast and vacuole. We find that the highly predominant protein families of tuber, patatins (lipase activity) and Kunitz-motive protease inhibitors, have cultivar dependent gene and protein sequences. Therefore, the present impressive number of 38,239 potato unigenes derived largely from ESTs of several tetraploid potato cultivars will overestimate the total number of genes in potato (www.tigr.org). Patatins and protease inhibitors are assigned both protein storage and defence functions, and their extensive variation is most likely a result of breeding. Enzymes of starch biosynthesis are much more conserved in sequence.

Acknowledgements: Supported by the Danish Technical Research Council (26-00-0141), and The Danish Veterinarian and Agricultural Research Council (23-02-0034).

References: Crookshanks M, Emmersen J, Welinder KG, Nielsen KL (2001) The potato tuber transcriptome: analysis of 6077 expressed sequence tags. FEBS Lett 506, 123-126. Rune Matthiesen, Jakob Bunkenborg, Allan Stensballe, Ole N. Jensen, Karen G. Welinder, Guy Bauw (2004) Database-independent, database-dependent, and extended interpretation of peptide mass spectra in VEMS V2.0. Proteomics, 4, 2583-2593. Rune Matthiesen, Guy Bauw and Karen G. Welinder (2004) Use of Performic Acid Oxidation To Expand the Mass Distribution of Tryptic Peptides. Anal Chem 76, 6848-6852. Nielsen KL, Grønkjær K, Welinder KG, Emmersen J (2005) Global transcription profiling of potato tuber using LongSAGE. Plant Biotechnol J. 3, 175-185. Contact: www.bio.aau.dk/en/biotechnology/ 


\section{Posters: Products}




\section{Posters: Products}

\section{Occurrence of rhodiocyanosides and related compounds in plants and implications for herbal medicine}

Nanna Bjarnholt, Karina Jessing, Kristina Refsgaard, Charlotte Jørgensen, Søren Bak, Nils Brünner, Per Stahl Skov, Birger Lindberg Møller.

The nitril glucosides, rhodiocyanosides $A$ and $D$, were previously identified in roots from Rhodiola species used in traditional herbal medicine for treatment of coughs and skin wounds. They were also reported to inhibit histamine release from rat peritoneal cells. In this study plant extracts known for similar properties or glucoside contents were analysed for rhodiocyanosides and co-ocurring cyanogenic glucosides linamarin and lotaustralin. Rhodiola rosea, the foremost variety in herbal medicine, proved to contain lotaustralin and the rhodiocyanosides and so did commercial Rhodiola rosea tablets. Contents in roots varied from a few $\mu \mathrm{g} / \mathrm{g} \mathrm{FW}$ to $5000 \mu \mathrm{g} / \mathrm{g}$ FW.

Extracts of red clover flowers are likewise used against coughs and for skin healing. We demonstrated that linamarin and lotaustralin were present in flowers, shoots and leaves with maximum levels around $3 \mu \mathrm{g} / \mathrm{g} \mathrm{FW}$, but not the rhodiocyanosides. White clover is a highly potent source of linamarin and lotaustralin but was not found to produce the rhodiocyanosides either.

The rhodiocyanoside aglucons have previously been isolated from black currant buds. We found that leaves, buds and berries from several species of the Ribesfamily contain lotaustralin and rhodiocyanosides up to $500 \mu \mathrm{g} / \mathrm{g} \mathrm{FW}$.

Lotus japonicus contains up to $2 \mathrm{mg} / \mathrm{g}$ FW of the four glucosides and Lotus and Rhodiola extracts as well as the purified compounds were assayed for inhibition of histamine release. Initial trials indicated that the plant extracts inhibited anti-lgE induced histamine release from human basophile granulocytes. However, the purified glucosides inhibited netiher anti-lgE induced histamine release from human basophile granulocytes or 48/80 induced histamine release from rat peritoneal cells (Sprague Dawly males, weight ca. $200 \mathrm{~g}$ ). In the previous studies using peritoneal cells from male Wistar rats (350-500 g) a substantial inhibition from plant extracts as well as purified lotaustralin and rhodiocyanosides was observed. 


\section{Posters: Products}

\section{Cellular localization of mRNAs encoding enzymes involved in cyanogenic glucoside metabolism in sorghum, Sorghum bicolour, and cassava, Manihot esculenta}

Kirsten Jørgensen and Birger Lindberg Møller,

The Royal Veterinary and Agricultural University,Department of Plant Biology Plant Biochemistry Laboratory, KVL

The localization of mRNAs encoding enzymes in synthesis (CYP79A1, CYP71E1 and UGT85) and degradation (Dhurrinase $1 \& 2$ ) of dhurrin in sorghum, Sorghum bicolor, and of (CYP79D1 \& D2) encoding the first step in linamarin/lotaustralin synthesis in cassava, Manihot esculenta, has been studied with a modified in situ PCR

In the first leaf of sorghum seedlings, CYP79A1, CYP71E1 and UGT85 co-localize in specific cells primarily in the epidermis cell layer. Dhurrinase $1 \& 2$ are preferentially expressed in dark and light grown seedlings respectively. For both enzymes bundle sheath cells were the prime site of localization.

In the top leaf of 3 month old green house grown cassava CYP79D1 \& D2 were found to be expressed in specific cells situated 1-2 rows below epidermis. The expression closest to the upper epidermis is in the second row from epidermis and for the lower part of the leaf it is seen in the first cell row after epidermis. In addition expression in parenchymatic cells in the stele was observed.

This procedure can as well as localization studies be used to find appropriate promoters to be used in our work producing acyanogenic cassava. 


\section{Posters: Products}

\section{Engineering of novel tryptophan derived natural products in transgenic}

\section{Arabidopsis thaliana}

Marc Morant, Carl Erik Olsen, Birger Lindberg Møller and Søren Bak

The Royal Veterinary and agricultural University, Department of Plant Biology Center for molecular Plant Physiology

40 Thorvalsensvej, DK-1871 Frederiksberg, Denmark

Cyanogenic glucosides are amino acid-derived secondary metabolites found in a large number of plant species. In sorghum, the biosynthetic pathway for the tyrosinederived cyanogenic glucoside dhurrin, involves only two cytochromes P450 CYP79A1 and CYP71E1 and one UDP glucosyl-transferase UGT85B1 and is therefore ideally suited for metabolic engineering. Arabidopsis thaliana does not produce cyanogenic glucosides but accumulates glucosinolates, another class of amino acid-derived natural products that have oximes as intermediates. Cyanogenic glucosides-derived from tryptophan have not been identified in plant whereas tryptophan-derived glucosinolates are well-known. We have engineered $A$. thaliana to produce a tryptophan-derived cyanogenic glucoside by redirecting the flux of indole-3-acetaldoxime from indole glucosinolate synthesis into cyanogenic glucoside synthesis by expression of CYP71E1 and UGT85B1. Rnt1-1/sur2 plants knocked out in the second step of the indole-glucosinolate pathway (CYP83B1) show a high indole-3-acetic acid (IAA) phenotype due to an increase of indole-3-acetaldoxime content. Insertion of CYP71E1 and UGT85B1 re-direct excess of indole-3acetaldoxime towards cyanogenic glucoside synthesis. In our analyses, metabolites were extracted from 10 days old plants grown on MS medium and analyzed by LCMS. Changes in the metabolome were monitored between the different lines and appearance of new tryptophan-derived metabolites revealed the presence of the new pathway. 


\section{Posters: Products}

6. Relaxation in a stressful environment: Methods for probing and analyzing the mechanical properties of cell walls of turgid, living plant cells.

Peter Ulvskov' ${ }^{1}$, Steen L. Hansen ${ }^{2}$, Anders O. Karlsson ${ }^{3}$, Bodil Jørgensen ${ }^{1}$, Bernhard Borkhardt ${ }^{1}$, Kirsten Faber ${ }^{1}$, Iben Damager ${ }^{1}$, Bent L. Petersen ${ }^{1}$

${ }^{1}$ Biotechnlogy Group, DIAS

${ }^{2}$ Department of Natural Sciences, KVL

${ }^{3}$ Department of Food Science, KVL

The turgor pressure of plant cells is usually in the range from 0.2 to $1 \mathrm{MPa}$ (a bicycle tire is typically inflated to $5 \mathrm{~atm} . \approx 0.48 \mathrm{MPa}$ ). The cell wall sustains this pressure and expands by yielding to this pressure in a highly regulated fashion as the cell grows. The structures of the individual wall components have been characterized in considerable detail whereas the organization of the wall components and the mechanisms of regulated relaxation of the load bearing structures in wall are poorly understood.

We have applied the frequency sweep method to living potato tuber tissue in order to determine the mechanical properties of the tissue and make inferences about the flow properties of matrix polysaccharides in the wall. The method comprises the recording of elastic and viscous responses of the tissue as it is subjected to oscillating deformations at different frequencies.

The interpretation of the experimental data can be done through transformation of the data into a spectrum of relaxation times. This transformation is not trivial due to three main reasons: i) the measurements are made in a limited range of frequencies, ii) the measurements are relatively noisy, and iii) the exact mathematical relation between the relaxation times and the elastic and viscous properties of the tissue is not known, so an approximation must be used. This means that a given measurement is consistent with an infinite number of different relaxation spectra. However by combining the experimental data with some prior information or assumption the (single) relaxation spectrum having the maximum posterior probability can be estimated.

Recording relaxation spectra of transgenic potato tissues, which are reduced in particular pectic epitopes and comparing them to the wild type relaxation spectrum, allow us to relate features of the relaxation spectrum to the structure of the pectic matrix. The implications for wall architecture will be discussed. 


\title{
Posters: Products
}

\section{Cellular localization of biosynthesis and breakdown of cyanogenic glucosides in Lotus japonicus}

\author{
Anne Vinther Rasmussen ${ }^{1}$, Winnie Dam², Birger Lindberg Møller ${ }^{1}$, Bodil Jørgensen ${ }^{2}$ \\ and Søren Bak ${ }^{1}$ \\ ${ }^{1}$ Royal Veterinary and Agricultural University, Center for Molecular Plant Physiology \\ (PlaCe), Plant Biochemistry Laboratory, 40 Thorvaldsensvej, DK-1871 Frederiksberg \\ $C$, Copenhagen, Denmark \\ ${ }^{2}$ Biotechnology Group, Danish Institute of Agricultural Sciences, 40 Thorvaldsensvej, \\ DK-1871 Frederiksberg C, Copenhagen, Denmark
}

Cyanogenic glucosides are amino acid derived natural products playing a role in plant-microbe and plant-herbivore interactions. Lotus japonicus aerial parts contain two cyanogenic glucosides, linamarin and lotaustralin and the nitrile glucosides rhodiocyanoside A and D. The two cytochromes P450, CYP79D3 and CYP79D4 share $94 \%$ identity at the amino acid level, and catalyze the first committed step in biosynthesis of both the cyanogenic- and nitrile glucosides in L. japonicus. RT-PCR analysis showed that CYP79D 3 was expressed in aerial parts of $L$. japonicus whereas CYP79D4 expression was observed in roots. Analysis of $L$. japonicus transformed with a GFP-GUS construct under control of either the CYP79D3 or the CYP79D4 promoter revealed that CYP79D3 is expressed in petioles, stem and faintly in roots, but not in leaflets. CYP79D4 is expressed in roots and in cells surrounding vascular tissue in aerial parts. Upon cellular disruption, the cyanogenic glucosides are broken down by $\beta$-glucosidases resulting in release of toxic hydrogen cyanide. The $\beta$-glucosidases in $L$. japonicus have high affinity towards lotaustralin and rhodiocyanosides $A$ and $D$, but low affinity towards linamarin. In-tissue assays revealed high $\beta$-glucosidase activity in leaflet palisade cells, less in sponge tissue and no activity in epidermis cells.

The intricate cellular organization of this binary system- two components that separately are chemically inert- enables plants to release a "cyanide bomb" as an immediate chemical defense response to herbivores and pathogens that cause tissue damage. 


\section{Posters: Products}

\section{Structure and function of selected fungal, mammalian and plant starch binding domains from the CBM20 family}

Camilla Christiansen1, Esben Friis2, Lone Baunsgaard1, Anders Viksø-Nielsen2, Birte Svensson3, Henrik Næsted3, Hannes Lohi4 and Andreas Blennow1

1 Center for Molecular Plant Physiology (PlaCe), Plant Biochemistry Laboratory, Department of Plant Biology, The Royal Vet. and Agric. University, DK-1871 Frederiksberg C, Copenhagen, Denmark (cch@kvl.dk)

2 Novozymes A/S, Krogshøjvej 36, DK-2880 Bagsværd, Denmark

3 Biochemistry and Nutrition Group, BioCentrum-DTU, Technical University of Denmark, Søltofts Plads, building 224, DK-2800 Kgs. Lyngby, Denmark

4 Department of Genetics and Genome Biology, The Hospital for Sick Children, 555 University Avenue Toronto, Ontario, M5G 1X8, Canada

Specific starch metabolising enzymes have starch binding domains connected to the catalytic domain either in the $\mathrm{C}$ - or in the $\mathrm{N}$-terminal part of the polypeptide chain. SBDs are typically around 100 amino acid residues long and the polypeptide folding is well conserved among different enzymes as well as among different species. The SBDs are classified into CBM family 20,21, 25 and 26 based on their primary structure (CAZy; http://afmb.cnrs-mrs.fr/CAZY/index.html).

The main function of SBD is to attach to granular starch and increase the local concentration of the substrate to the binding site [1]. The SBD in glucoamylase (GA) from Aspergillus niger can bind to amylose chains forming nano-size ring shapedstructures as seen by AFM [2]. Such structures are also formed by catalytically inactive glucoamylase. Possibly the SBD has the capacity to break native starch granular structures thereby exposing nano-sized starch motifs as substrate for the enzyme. The precise influence of SBD on starch degradation as well as its mechanism of action, however, remains to be elucidated.

Phylogenetic analysis of SBD sequences has revealed a small subfamily including the putative SBD from one of the plant glucan water dikinases (GWD) [3] and a CBM20 recognized in the human protein phosphatase called Laforin [4]. We have expressed in E. coli the SBDs from $A$. niger GA, $A$. thaliana GWD3 and $H$. sapiens LAF. A preliminary study on the affinity towards starch of these SBDs was carried out. Three-dimensional homology models of the GWD3 and the Laforin SBDs were created using the 3D structure of the SBD from the $A$. niger GA SBD and the CGTase from $B$. circulans 251 respectively, as template. In the forthcoming studies starch binding domains from GWD3, Laforin and GA will be fused to the catalytic domain of GA, to create new chimeric proteins with engineered starch binding properties. These fusion proteins will be examined for there ability to bind to and hydrolyse starch granules.

\section{References}

1. Sauer J, Sigurskjold BW, Christensen U, Frandsen TP, Mirgorodskaya E, Harrison M, Roepstorff P, Svensson B. 2000. Glucoamylase: structure/function relationships, and protein engineering. Biochim. Biophys. Acta 1543, 275-293.

2. Giardina,T., Gunning, A.P., Juge, N., Faulds, C.B., Furniss, C.S.M., Svensson, B., Morris, V.J., and Williamson, G. 2001. Both binding sites of the starch-binding domain of Aspergillus niger glucoamylase are essential for inducing a conformational change in amylose. Journal of Molecular Biology 313: 1149-1159. 


\section{Posters: Products}

3. Mikkelsen, R., Baunsgaard, L. and Blennow, A. 2004. Functional characterization of alpha-glucan,water dikinase, the starch phosphorylating enzyme. Biochem. J. 377. $525-532$

4. Ganesh, S., Tsurutani, N., Suzuki, T., Hoshii, Y., Ishihara, T., gado-Escueta, A.V., and Yamakawa, K. 2004. The carbohydrate-binding domain of Lafora disease protein targets Lafora polyglucosan bodies. Biochem. Biophys. Res. Commun. 313: 11011109. 



\section{Posters: Productivity}




\section{Posters: Productivity}

\section{A previously found thylakoid membrane protein of $14 \mathrm{kDa}$ (TMP14) is a novel subunit of plant photosystem I and is designated PSI-P}

Anastassia Khrouchtchova ${ }^{1}$, Maria Hansson ${ }^{2}$, Virpi Paakkarinen ${ }^{3}$, Julia P. Vainonen ${ }^{2,3}$, Suping Zhang ${ }^{1,4}$, Poul Erik Jensen ${ }^{1}$, Henrik Vibe Scheller ${ }^{1}$, Alexander V. Vener ${ }^{2}$, EvaMari Aro ${ }^{3}$ and Anna Haldrup ${ }^{1, \star}$

${ }^{1}$ Plant Biochemistry Laboratory, Department of Plant Biology, The Royal Veterinary and Agricultural University, 40 Thorvaldsensvej, DK-1871 Frederiksberg C, Copenhagen, Denmark

${ }^{2}$ Division of Cell Biology, Faculty of Health Sciences, Linköping University, SE58185 Linköping, Sweden

${ }^{3}$ Department of Biology, Plant Physiology and Molecular Biology, University of Turku, Turku FI-20014, Finland

${ }^{4}$ Present address: Department of Biology, The University of Western Ontario, London, Ontario, N6A 5B7, Canada

Photosystem I (PSI) is a pigment-protein complex located in the photosynthetic membranes. It functions as an oxido-reductase, which accepts an electron on the luminal side delivered from PSII through a series of electron carriers and transfers it to the outer side of the membrane. There the electron is used to reduce NADP ${ }^{+}$which in turn will be used primarily for $\mathrm{CO}_{2}$ assimilation. PSI is present in oxygen-evolving organisms such as cyanobacteria, algae and higher plants and its proper functioning is mediated by the intricate interplay of multiple subunits. Plant PSI is currently known to be composed of 14 core subunits (PSI-A to $-\mathrm{L}, \mathrm{PSI}-\mathrm{N}$ and PSI-O) and $4 \mathrm{LHCl}$ antenna proteins (Lhca1-4).

Recently, Arabidopsis PSI-D was reported to be the first phosphorylated PSI subunit found. Along with the discovery of PSI-D phosphorylation, a thylakoid membrane phosphoprotein of $14 \mathrm{kDa}$ (TMP14, At2g46820) with unknown function was reported. We have shown that TMP14 is a novel subunit of plant PSI and designated it PSI-P. Blue Native/SDS-PAGE and sucrose gradient fractionation demonstrated the association of the protein exclusively with PSI. The presence of PSI-P subunit in Arabidopsis mutants lacking other PSI subunits was analyzed and suggested a location in the proximity of PSI-L,-H and -O subunits. The PSI-P protein is not differentially phosphorylated in state 1 and state 2 . 


\title{
Posters: Productivity
}

\section{Gene expression analysis of leaf senescence in wheat}

\author{
Per L. Gregersen and Preben B. Holm
}

Department of Genetics and Biotechnology, Danish Institute of Agricultural Sciences. (per.gregersen@agrsci.dk)

The senescence processes in cereals play an essential role for completion of the maturation of the crop, which ends in a dead plant with the exception of the harvested, viable seed. During development and maturation of the seed, nutrients are translocated from the whole plant, and the senescence processes in the distal, vegetative plant parts make remobilisation of nutrients possible through degradative processes. In order to study the complexity of these processes, we have performed cDNA microarray studies of the gene expression patterns in flag leaves of wheat. In a time-course from full expansion to wilting of the leaf, four general patterns of gene expression essentially emerged: One pattern showed a gradual decrease in gene expression levels, primarily comprising genes involved in photosynthsis. This pattern was mirrored by a pattern showing a gradual increase in expression levels, comprising stress-related genes for both degradative and protective processes. A third general pattern had steady levels of expression until the end of the time-course when it dramatically decreased. This pattern primarily comprised general house-keeping genes. It was mirrored by a pattern with a high increase in expression levels towards the end of the time-course. Here, clearly many of the genes were involved in degradative and remobilization processes, such as proteolytic and hydrolytic processes. Among the regulated genes during the senescence process are also genes for transcription factors and other regulatory components. In our future studies we will have a focus on these genes and their role in the regulation of the senescence process. 


\title{
Posters: Productivity
}

\section{Developing a feed barley with improved amino acid composition to meet environmental and nutritional demands}

\author{
Mette Lange, Eva Vincze, Preben Bach Holm \\ Danish Institute of Agricultural Sciences, Department of Genetics and Biotechnology, \\ Forsøgsvej 1, 4200 Slagelse, Denmark
}

The major group of storage proteins in barley, the hordeins, has a low nutritional value due to a low content of several essential amino acids especially lysine, methionine, threonine and tryptophan. Hordeins on the other hand possess large amounts of the non-essential amino acids proline and glutamine that cannot be utilized but are degraded and the nitrogen secreted in the urine making a significant contribution to the environmental nitrogen load.

Hordeins consist primarily of two types, i.e. the sulphur poor C-hordeins and the sulphur rich $\mathrm{B}$-hordeins. As the $\mathrm{C}$-hordeins in particular are deficient in essential amino acids and at the same time has a very high content of proline and glutamine we have explored the possibilities of selectively suppressing the formation of C-hordeins.

We utilized a conventional antisense approach and generated transgenic lines expressing an antisense $\mathrm{C}$-hordein gene. The generated lines expressed the transgene and we have identified a number of lines where the C-hordein levels are reduced (on average $20 \%$ ). The reductions were accompanied by an increase in glutelin. Proline was reduced by $12 \%$ and glutamine by $6 \%$ while there was a $16 \%$ increase in lysine.

The current strategy may allow for the production of feed barley with an improved nutritional and environmental profile. In addition, the transgenic lines will be very valuable tools for getting insight into the regulation of amino acid and storage protein biosynthesis in the barley grain. 


\section{Posters: Productivity}

\section{Vesicle trafficking and abiotic stress}

\section{Angela Feechan, Zigou Zhang, Jin-long Qiu, Helge Tippmann, Carsten Pedersen and}

Hans Thordal-Christensen

Dept. of Agricultural Sciences, The Royal Veterinary and Agricultural University, Thorvaldsensvej 40, 1871 Frederiksberg C, Copenhagen, Denmark

SNAREs drive secretory vesicle targeting and fusion. Recently syntaxins from the SNARE (Soluble N-ethylmaleide-sensitive factor (NSF) adaptor protein) superfamily have been implicated in plant adaptation to both abiotic and biotic stress responses (Pratelli et al., 2004).

The Arabidopsis Syntaxin of Plants121 (AtSYP121) was previously shown to be required for non-host resistance to barley powdery mildew (Collins et al., 2003). NtSyr1 which is the tobacco homolog of AtSYP121 was shown to block abscisic acid (ABA) mediated $\mathrm{Cl}^{-}$ and $\mathrm{K}^{+}$channel responses in guard cells, implicating a role for $\mathrm{NtSyr}$ in drought responses (Leyman et al., 1999).

Therefore we have been investigating the role of the plasma membrane SYP121 and the closely related syntaxin SYP122 in abiotic stress responses. We have found that syp121 and syp121syp122 double mutant seedlings show increased sensitivity to ABA.

The double mutant syp121syp122 shows increased salt sensitivity compared to wild type Col-0 seedlings. Thus we are currently studying the molecular basis of the altered salt responses found in the syntaxin mutants. 


\section{Posters: Productivity}

7. The properties of the positively charged loop region in PSI-G are essential for its "spontaneous" insertion into thylakoids and rapid assembly into the PSI complex

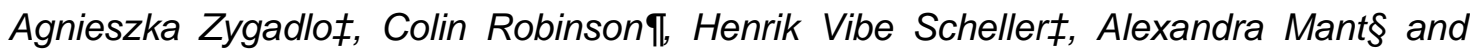
Poul Erik Jensen $\neq$

‡Plant Biochemistry Laboratory, Department of Plant Biology, The Royal Veterinary \& Agricultural University, Frederiksberg, Denmark and, Cancer Sciences Division, Southampton General Hospital, Mailpoint 824, Tremona Road, Southampton, SO16 6YD, UK and IDepartment of Biological Sciences, University of Warwick, Coventry CV4 7AL, UK

The PSI-G subunit of photosystem I (PSI) is an $11 \mathrm{kDa}$ membrane protein which plays an important role in electron transport between plastocyanin and PSI, and is involved in the stability of the PSI complex (Zygadlo et al., 2005). Within the complex, the PSI-G subunit is bound to PSI-B and is in contact with Lhca1. PSI-G has two transmembrane spans connected by a positively charged stromal loop. The loop is inaccessible to proteases, indicating a buried location within the PSI complex. Here, we have studied the insertion mechanism and assembly of PSI-G. We show that the protein inserts into thylakoids by a direct or "spontaneous" pathway that does not involve the activities of any known chloroplast protein targeting machinery. Surprisingly, the positively charged stromal loop region plays a major role in this process. Mutagenesis or deletions within this region almost invariably lead to a marked lowering of insertion efficiency, strongly indicating a critical role for the loop in the organisation of the transmembrane regions prior to, or during membrane insertion. Finally, we have examined the assembly of newly-inserted PSI-G into the PSI complex, since very little is known of the assembly pathway for this large multimeric complex. Interestingly, we find that inserted PSI-G can be found within the full PSI complex only a few minutes after insertion into thylakoids, strongly suggesting that PSI-G normally associates at the end of the assembly process. This is consistent with its location on the periphery of the complex. 


\section{Posters: Productivity}

\section{PSI-J of photosystem I is required for efficient electron transport and stability of the multiprotein complex}

Poul Erik Jensen $^{1}$, Katrin Amann ${ }^{2}$, Andreas Hansson $^{1}$, Agnieszka Zygadlo $^{1}$, and Jörg Meurer $^{2}$

${ }^{1}$ Plant Biochemistry Laboratory, Department of Plant Biology, The Royal Veterinary and Agricultural University, Thorvaldsensvej 40, DK-1871 Frederiksberg C, Denmark.

${ }^{2}$ Ludwig-Maximilians-Universität-München, Department Biologie I, Botanik, Menzingerstr. 67, 80638 München, Germany

In plants the core of photosystem I (PSI) consists of at least 15 different protein subunits named PSI-A to PSI-L, PSI-N and PSI-P. The low molecular mass membrane integral subunits do not directly bind co-factors involved in electron transport but instead fulfill other functions such as stabilization of the core antenna system, binding of the peripheral antennas and interaction with soluble electron transporters.

Here we present work on plants in which the chloroplast encoded PSI-J subunit has been eliminated by chloroplast transformation using a knockout allele for targeted disruption of the tobacco psaJ gene. PSI-J is a $5 \mathrm{kDa}$ protein which spans the thylakoid membrane once, binds 2 chlorophyll molecules and is located close to PSI-F. Plants devoid of PSI-J are fully viable and fertile but are approximately 10\% smaller than WT and have slightly paler leaves. This is evidenced by $10-15 \%$ less chlorophyll per leaf area. Immuno-blotting using antibodies directed against the various thylakoid protein complexes reveals that plants devoid of PSI-J has approximately 40-50\% less PSI which is confirmed by a similar increase in chlorophylls per PSI reaction center. Thus, PSI seems to be less stable in the absence of PSI-J. The absence of PSI-J does not affect the binding of $\mathrm{LHCl}$ to PSI since the functional antenna size of PSI is unaffected by the elimination of PSI-J. Instead, in vitro $\mathrm{NADP}^{+}$photo-reduction measurements clearly indicate a role of PSI-J in electron transfer efficiency. PSI-J is located away form the electron transport chain and the observed effect on electron transfer efficiency must be caused by a secondary effect on other subunits of the complex. Work is in progress to analyze this further. 


\title{
Posters: Productivity
}

\section{From yellow to green by restoring the chlorophyll supply: in vivo and in vitro}

\author{
Andreas Hansson and Poul Erik Jensen \\ The Royal Veterinary and Agricultural University, Department of Plant Biology, Plant \\ Biochemistry Laboratory, 40 Thorvaldsensvej, DK-1871 Frederiksberg C, Copenhagen, \\ Denmark.
}

\begin{abstract}
A SALK line (ch/27) carrying a T-DNA insert in the promoter region of CHL27, the Arabidopsis homologue to Chlamydomonas Crd1, has a chlorotic phenotype. Compared with wild-type the chlorophyll level is reduced by $70 \%$ and the chlorophyll a/b ratio is increased twofold. Electron micrographs of the chloroplast ultrastructure revealed a twofold increase in the proportion of stroma lamellae and $40 \%$ decrease in grana membranes. Blue-native PAGE and western blot analysis demonstrated an almost complete loss of LHCII protein and a significant reduction of PSI in chl27.
\end{abstract}

Upon feeding plants with ALA in darkness, chl27 accumulate Mg-protoporphyrin IX monomethylester, indicating that CHL27 is required for protochlorophyllide synthesis. This makes CHL27 a candidate subunit of the aerobic cyclase. Biochemical and genetical characterisations has previously shown that at least two or three protein components are required for aerobic cyclase activity. An in vitro assay based on barley etioplasts has been developed. The activity is dependent on combination of membrane protein fraction, soluble protein fraction, $\mathrm{NADPH}, \mathrm{O}_{2}$ and the porphyrin substrate. Further, the activity is enhanced several fold upon addition of catalase, a scavenger of $\mathrm{H}_{2} \mathrm{O}_{2}$. Eventually further fractionation will lead to the identification the remaining unknown protein components of the aerobic cyclase.

When the chl27 cDNA controlled by an E35S promoter is introduced, the ch/27 plant recover and get indistinguishable from wild-type regarding chlorophyll level, chlorophyll $\mathrm{a} / \mathrm{b}$ ratio and $77 \mathrm{~K}$ fluorescence. Our aim is to construct a plant with an inducible expression of CHL27 and to use the recovery phase to study the assembly of pigmentprotein complexes. 



\section{Posters: Nutrition}




\section{Posters: Nutrition}

\section{Ammonium: The paradox plant nutrient}

Floor ten Hoopen, Jan K. Schjørring, and Thomas P Jahn

Plant and Soil Science Laboratory, Department of Agricultural Sciences, The Royal Veterinary and Agricultural University, Thorvaldsensvej 40, DK-1871 Frederiksberg C, Denmark

Ammonium $\left(\mathrm{NH}_{4}{ }^{+} / \mathrm{NH}_{3}\right)$ is a central intermediate for nitrogen assimilation in both plants and animals. However, elevated $\mathrm{NH}_{4}{ }^{+}$is potentially toxic and has been linked to $\mathrm{NH}_{3}$ volatization from plant folia and loss in nitrogen use efficiency. We have studied on the molecular level the transport of $\mathrm{NH}_{4}{ }^{+} / \mathrm{NH}_{3}$ across membranes to better understand ammonium toxicity and nitrogen use efficiency. Using heterologous expression in yeast and oocytes, selected members of the aquaporin super family have been identified able to transport $\mathrm{NH}_{3}$, hence aquaammoniaporins. Aquaammoniaporins have been localized to the tonoplast, the peribacteroid membrane, the chloroplast inner membrane and the plasma membrane. The observation of facilitated diffusion of $\mathrm{NH}_{3}$ was initially puzzling, since a large body of physiological data in the literature suggests that $\mathrm{NH}_{4}{ }^{+}$is the main form transported across the plant plasma membrane. The presence of both $\mathrm{NH}_{4}{ }^{+}$ uptake and $\mathrm{NH}_{3}$ release at the plasma membrane would be problematic, since the transport may result in the collapse of the proton motive force or the membrane potential. Here we present data from yeast and Arabidopsis, strongly suggesting that some $\mathrm{K}^{+}$transporters can transport $\mathrm{NH}_{4}{ }^{+}$and that this transport under high ammonium and low potassium supply is toxic to both yeast and Arabidopsis. Our data suggest that transport of $\mathrm{NH}_{4}{ }^{+}$through $\mathrm{K}^{+}$transporters may represent a major thread leading to ammonium toxicity and reduced nitrogen use efficiency. 


\title{
Posters: Nutrition
}

\section{Comparative analysis of barley hordein $C$ antisense lines using "pathway specific" microarrays}

\author{
Michael Hansen, Mette Lange, Eva Vincze, Preben Bach Holm
}

Danish Institute of Agricultural Sciences, Department of Genetics and Biotechnology, Research Centre Flakkebjerg, 4200 Slagelse, Denmark

Barley, is low in several essential amino acids (AA), lysine, methionine, threonine and tryptophan and high in the non-essential AA, glutamine and proline which negatively affects its utility as feed for both ruminant and monogastric animals. Changing the proportion among the storage protein families can favourably alter the AA profile. The complexity of AA and storage protein metabolism and the pleiotropic effects in mutants warrants the implementation of global techniques for elucidating the key regulatory mechanism.

We examined the effects of expressing an antisense Hordein $C$ construct in the barley genome to find out how the interconnected metabolic pathways changed. We used gene expression analysis and developed a pathway specific cDNA microarray.

A hypothetical model of the interconnected pathways was validated in the obtained expression profiles. The transgenic barley lines showed lower Hordein $C$ levels and down regulated transcriptencoding hordein $C$, while the production of the S-rich hordeins $B, D$ and gamma were increased with significant up regulation of the corresponding gene expression levels. The synthesis of S-rich hordeins increased the demand for sulphur and S- rich AAs, cysteine and methionine. We observed up-regulation of key enzymes: sulphite reductase, catalase and S-adenosylmethionine synthetase. Similarly, the presence of a higher level of glutelin, lysine, histidine, and tyrosine correlated with a significantly overexpression of the corresponding genes.

Through microarray analysis, the understanding of the complex regulation of AA metabolisms could provide the knowledge required for further alteration of the AA profile in barley and increase its utility as animal feed. 


\section{Posters: Nutrition}

\section{Stopped-flow measurements of water and ammonia fluxes in yeast spheroplast expressing various aquaporins}

A.L.B. Møller, G.P. Bienert, Jan K. Schjørring, and Thomas P Jahn

Plant and Soil Science Laboratory, Department of Agricultural Sciences, The Royal Veterinary and Agricultural University, Thorvaldsensvej 40, DK-1871 Frederiksberg C, Denmark

Aquaporins (AQPs) belong to the Major Intrinsic Protein (MIP) family, a large and diverse group of membrane proteins, which facilitate transport of water and small solutes across membranes. 35 full-length MIPs have been identified in Arabidopsis thaliana, and 13 AQPs have been found in human. Various new substrates have recently been identified for selected members in both plants and mammals. While water seems to be a general substrate to many or even all members, other substrates such as urea, $\mathrm{CO}_{2}$ and $\mathrm{NH}_{3}$ are restricted to a rather limited number of isoforms. Water transport through AQPs can be measured as rapid volume changes of vesicles or liposomes containing AQPs with the help of a rapid kinetics instrument (stopped flow). The measurement itself is relatively straight forward, but the sample preparation is usually tedious and involves biochemical purification of membranes or even proteins followed by reconstitution. The yields are usually low and the procedure is time and money consuming. To minimize these problems, we have developed a new method to measure fluxes of water and potentially other substrates by means of rapid volume changes of yeast spheroplasts. Yeast cells can easily be transformed with single isoforms from various organisms and can be grown to large amounts. After simple cell wall digestion the resulting yeast spheroplast can directly be used in stopped flow assay. Currently, we are using sorbitol, potassium sulfate and ammonium sulfate to induce and control the flux of water and ammonia and here we present some results from human AQP1, AQP8, Arabidopsis PIP2;1 and TIP1;1. 


\section{Posters: Nutrition}

\section{Differential Mn efficiency in barley genotypes is related to differences in Mn uptake capacity in the low $\mathrm{nM}$ concentration range}

Pedas $P$, Jahn TP, Schjørring JK and Husted S

Plant and Soil Science Laboratory, Department of Agricultural Sciences, The Royal Veterinary and Agricultural University

There is considerable variability among barley (Hordeum vulgare L.) genotypes in their ability to grow on soils containing low levels of plant available manganese (Mn). The physiological basis for this tolerance to low $\mathrm{Mn}$ availability is unknown. In the present work $\mathrm{Mn}^{2+}$ influx in barley roots of the $\mathrm{Mn}$ efficient genotype Vanessa and the $\mathrm{Mn}$ inefficient genotype Antonia was examined. Two separate $\mathrm{Mn}$ transport systems, mediating high-affinity $\mathrm{Mn}^{2+}$ influx between 0.1-130 $\mathrm{nM}$ and lowaffinity $\mathrm{Mn}^{2+}$ influx at higher concentations, respectively, were identified in both genotypes. The two genotypes differed only in high-affinity kinetics with the Mn efficient genotype having almost four times higher $V_{\max }$ than the inefficient genotype, but similar $\mathrm{K}_{\mathrm{m}}$ values. This difference was further documented in long-term Mn uptake experiments where plants were exposed to chemostatic low $\mathrm{nM} \mathrm{Mn} \mathrm{concentrations.} \mathrm{It} \mathrm{is} \mathrm{concluded} \mathrm{that} \mathrm{differential} \mathrm{capacity} \mathrm{for} \mathrm{high-affinity} \mathrm{Mn}$ influx contributes to differences between barley genotypes in Mn efficiency. In addition, a molecular approach using a cDNA library and a yeast expression system has been initiated to identify putative candidates for $\mathrm{Mn}$ transporter proteins in barley roots which may be responsible for the $\mathrm{Mn}$ uptake. 


\section{Posters: Nutrition}

\section{TWO CANDIDATE AQUAPORINS SUGGESTED TO BE INVOLVED IN THE TRANSPORT OF $\mathrm{H}_{2} \mathrm{O}_{2}$}

Bienert, Gerd-Patrick; Schüssler, Désirée; Schjørring, Jan K. and Jahn, Thomas P. Plant and Soil Science Laboratory, Department of Agricultural Sciences, The Royal Veterinary and Agricultural University

Hydrogen peroxide $\left(\mathrm{H}_{2} \mathrm{O}_{2}\right)$, belonging to the reactive oxygen species, can react with various cellular targets thereby causing cell damage or even cell death. On the other hand, recent work from various laboratories has demonstrated that $\mathrm{H}_{2} \mathrm{O}_{2}$ functions as a signalling molecule controlling different essential processes in plants and mammals. As $\mathrm{H}_{2} \mathrm{O}_{2}$ is thought to be freely diffusible across membranes, diffusion was believed to be the exclusive way of transport. Contrary to this assumption recent studies pointed out that some membrane are only weakly permeable to $\mathrm{H}_{2} \mathrm{O}_{2}$. $\mathrm{H}_{2} \mathrm{O}_{2}$ transport across those membranes may thus be facilitated by either a change in the lipid composition or via facilitated diffusion through channel proteins.

Using various yeast mutants ( $\Delta t s a 1,2 ; \Delta y a p 1 ; \Delta s k n 7)$ compared to wild type with different sensitivities to exposure to $\mathrm{H}_{2} \mathrm{O}_{2}$, we identified aquaporins that, when expressed in yeast, increased the sensitivity to externally applied $\mathrm{H}_{2} \mathrm{O}_{2}$. A screening was performed using a total of 25 aquaporins homologues from plants and mammals. Yeast mutants transformed with either AtTIP1;1 or HsAQP8 increased the sensitivity to $\mathrm{H}_{2} \mathrm{O}_{2}$ by a factor of up to 10 fold suggesting a function in $\mathrm{H}_{2} \mathrm{O}_{2}$ transport. A more direct in vitro transport assays using $\mathrm{H}_{2} \mathrm{O}_{2}$ sensitive fluorescent probes and stopped flow fluorometry is currently under investigation.

Our results suggest that selected aquaporins play a role in the regulation of $\mathrm{H}_{2} \mathrm{O}_{2}$ distribution and may be important players in oxidative stress and apoptosis. 


\section{Posters: Nutrition}

\section{Wheat Ferritin: Fortification of wheat endosperm with bioavailable iron.}

Søren Borg, Stephanie C. Agius, Klaus Kristiansen and Preben Bach Holm, Department of Plant Biology, The Danish Institute of Agricultural Sciences, Research Centre Flakkebjerg, DK-4200 Slagelse, Denmark.

Dietary iron deficiency is a global problem afflicting about one third of the world's population. The strategies utilised to combat this micronutrient malnutrition such as food fortification, mineral supplements and dietary diversification are beneficial short-term solutions for effluent societies. However, in developing countries a long term, self sustainable approach would be the enrichment of iron in staple food products by traditional plant breeding, or modern genetic approaches.

Ferritin is an iron-storage protein common to animals, plants and bacteria. The iron is stored in a vesicle that consists of 24 polypeptide ferritin subunits where some 4000 iron atoms are sequestered.

We have cloned several different cDNAs coding for wheat ferritins. Alignment of the isolated fragments show that they are isoenzymes with an amino acid identity of more than $97 \%$. Using 3'Race it was possible to isolate the several different 3'-utr regions, allowing unique discrimination between the individual members of the ferritin gene family. The wheat ferritins divide into two main groups, TaFer1 and TaFer2, each representing one gene present in each of the three genomes in hexaploid wheat in agreement with the presence of two genes in maize, rice and barley. The two main group 3'utr's could further be divided into three subclasses, representing the three genomic isoforms. The presence of two genes with three homoeoalleles is further supported by the Southern blot analyses indicating that there is about 6 ferritin related sequences in the genome.

The corresponding genomic ferritin fragments including promoter sequence, have also been isolated by PCR techniques and sequenced. The structure of the encoded proteins shows the highest degree of homology to barley ferritins and both proteins have $\mathrm{N}$-terminal localization signals that direct them to plastids similar to other plant ferritins.

Real-time PCR were performed on leaves and three different stages of grain development. The wheat ferritin expression level is about five times lower in endosperm compared to leaves and the expression of the TaFer1 genes in both leaves and endosperm exceeds that of TaFer2 by a factor of 10-15.

To generate plants for increased expression of ferritin in the endosperm, future work include transformation of wheat with a genomic fragment representative wheat's own TaFer1 gene under the regulation of the endosperm specific glutenin promoter 1DX5.

The project is part of a Danish research program "Content and bioavailability of iron, zinc and vitamin A in commonly consumed foods in developing countries" supported by the Danish Foreign Aid Agency (DANIDA) and is associated with the international Challenge Biofortification Program "HarvestPlus" 


\section{Posters: Nutrition}

\section{Isolation and characterization of Lotus japonicus genes involved in iron and zinc homeostasis.}

Cristina Cvitanich, Winnie Jensen, Niels Sandal, Dorthe Bødkær Jensen, Hanne Busk, Søren Husted $^{*}$, Jens Stougaard, and Erik Østergaard Jensen. Department of Molecular Biology. University of Aarhus. Denmark. *Department of Agricultural Sciences, The Royal Veterinary and Agricultural University, Denmark

The goal of this project is to find ways to improve the nutritional value of legumes by identifying genes and proteins important for iron and zinc regulation in the model legume Lotus japonicus. Legumes are important staples in the developing world and are a major source of nutrients in many areas. Legumes are frequently grown in soil with limited nutrient availability.

Plants use finely tuned mechanisms to regulate levels of iron and zinc in different tissues. Several genes involved in iron and zinc homeostasis have been described in yeast, and a few orthologs have been studied in plants.

We have used these sequences to search for $L$. japonicus ESTs and genomic loci that are likely to be involved in iron and zinc metabolism. We have identified sequences corresponding to ferritin, ferric reductases, metal transport proteins of the ZIP family, cation transporters of the NRAMP family, and members of the yellow stripe family. The expression of these genes is being studied.

Furthermore, we are trying to map genes involved in metal homeostasis. We found significantly different levels of several micronutrients between Lotus filicaulis and $L$. japonicus Gifu. These differences will be used to map genes important for $\mathrm{Fe}, \mathrm{Zn}$, and $\mathrm{Cu}$ homeostasis using $L$. filicaulis $\mathrm{x} L$. japonicus Gifu recombinant inbred lines. 


\section{Posters: Nutrition}

\section{Loading of zinc into the developing barley grain}

\section{Birgitte Tauris, Søren Borg, Per L. Gregersen, Preben Bach Holm and Michael Gjedde Palmgren Department of Plant Biology, The Danish Institute of Agricultural Sciences, Research Centre Flakkebjerg}

The primary aim of this project is to study the genetic and molecular mechanisms underlying zinc transport and deposition in the cereal grain. Barley is used as model due to the post-genomic tools available for this plant.

In small-grained cereals, zinc is primarily stored as a phytate salt in vacuoles of the aleurone layer. The secondary depository is the embryo. The deposition pattern of zinc and also iron has far reaching consequences for human mineral nutrition. During milling the outer tissues and the embryo are removed from the grain, which results in a virtual depletion of both zinc and iron.

Zinc and iron are the most widespread micronutrient deficiencies in humans. These deficiencies are particularly common in developing countries where diets are rich in cereal-based foods, which serve as excellent suppliers of carbohydrates but is low in concentration of bioavailable zinc and iron. Some of the major health consequences of these deficiencies include retardation of growth, anaemia and impaired immune function. This is illustrated by the fact that in humans at least $3 \%$ of all genes encode proteins with zinc binding motifs and that in more than three hundred enzymes zinc is required as a co-factor.

The first task was the establishing of a barley microarray comprising as many genes as possible involved in zinc transport, deposition and homeostasis. This was accomplished by searching in barley EST databases for orthologs to all the zinc transporters, chelators etc. which had been identified and annotated as such in Arabidopsis and rice. We have established a zinc transcriptome array, which is based on unique oligonucleotides from 129 different ESTs belonging to 13 different gene families. This array will be used for expression studies of the zinc transcriptome in tissue sections of barley grains at different developmental stages coming from plants subjected to high and low zinc regimes.

In order to obtain an expression profile of the genes involved in zinc transport and deposition in specific tissues of the grain, the laser capture technique will be used. Using the laser technique we will be able to isolate individual cells from tissue sections, isolate RNA and prepare cDNA. The cDNA preparations will subsequently be used for microarray hybridisations and in real-time PCR analyses to establish the temporal and spatial expression patterns of particularly relevant genes.

$\mathrm{P}_{1 \mathrm{~B}}$ ATPases, encoded by HMA genes, are emerging as a new type of potentially important transporters of $\mathrm{Zn}, \mathrm{Cu}, \mathrm{Cd}$ and $\mathrm{Pb}$. In Arabidopsis it has been shown that individual knockout mutants does not exhibit an apparent phenotype, whereas hma2 hma4 double mutants have a nutrition deficiency phenotype that can be compensated for by increasing the level of $\mathrm{Zn}$, but not $\mathrm{Cu}$ or $\mathrm{Co}$, in the growth medium (Hussain et al., 2004). In collaboration with Annette Møller, KVL, we will generate transgenic barley plants where the HvHMA2 and HvHMA3 genes have been silenced by the RNAi technology and characterize the $\mathrm{Zn}$ transcriptome in these barley lines.

Hussain, D., Haydon, M.J., Wang, Y., Wong, e., Sherson, S.M., Young, J., Camakaris, J., Harper, J.F. and Cobbett, C.S. 2004. P-type ATPase heavy metal transporters with roles in essential zinc homeostasis in Arabidopsis Plant Cell 


\section{Posters: Nutrition}

\section{The physiological role of aquaporin TIP1 in Arabidopsis thaliana}

Désirée Schüssler, Floor ten Hoopen, Jan K. Schjørring, and Thomas P Jahn

Plant and Soil Science Laboratory, Department of Agricultural Sciences, The Royal Veterinary and Agricultural University, Thorvaldsensvej 40, DK-1871 Frederiksberg C, Denmark

The function of aquaporins in plants is a matter of recent investigation. According to the current view, aquaporins function in facilitating water transport for faster and more efficient uptake.

However, other substrates such as urea, $\mathrm{CO}_{2}$ and $\mathrm{NH}_{3}$ have recently been identified. Arabidopsis possesses 35 different aquaporin isoforms. Deletion of a single isoform is therefore not likely to generate a pronounced phenotype, since other isoforms may compensate for the loss of single isoforms. Accordingly, T-DNA insertion lines of AtTIP2;1 did not show any visible phenotype on various growth conditions. However, RNA $A_{i}$ plants downregulating the expression of AtTIP1; , an aquaporin localized to lytic type vacuoles, show a strong phenotype with early senescence depending on the degree of gene silencing (Ma, S. et al.; 2004). Using functional complementation and a yeast mutant deficient in ammonium uptake we could show that AtTIP1;1 can transport $\mathrm{NH}_{3}$ at physiologically relevant concentration. We therefore generated a Transposon insertion line for AtTIP1;1 to reinvestigate a potential role of TIP1;1 in lytic vacuole function, the nitrogen homeostasis and the transport of ammonia across vacuolar membranes.

Ma et al.; 2004: Loss of TIP1;1 aquaporin in Arabidopsis leads to cell and plant death. The Plant Journal 40, 845-859. 


\section{Posters: Nutrition}

\section{Design of phosphate nanosensors}

Hong Gu${ }^{1}$, Sylvie Lalonde ${ }^{2}$, Anne Marie Scharff-Poulsen ${ }^{3}$, Alexander Schulz ${ }^{1}$, Jens Kossmann ${ }^{4}$, Iver Jakobsen ${ }^{3}$ and Wolf B. Frommer ${ }^{2}$

${ }^{1}$ Department of Plant Biology, KVL; ${ }^{2}$ Plant Biology, Carnegie Institution, Stanford; ${ }^{3}$ Ris $\varnothing$ National Laboratory; ${ }^{4}$ Stellenbosch University, South Africa

Phosphate is an essential macronutrient for all living organisms present in a variety of structural, catalytic and regulatory molecules. To monitor phosphate levels in living tissue we have developed nanosensors that are based on fluorescence resonance energy transfer (FRET). These phosphate sensors (FLIPPi) consist of a bacterial phosphate binding protein fused to two variants of the green fluorescent protein. Fusion proteins were constructed in which bacterial phosphate binding proteins were used as sensor recognition element while CFP and YFP, fused to the protein via linker peptides, were used as the FRET reporter pair. The construction in which phosphate binding protein domain was from a Synechococcus strain yielded a functional phosphate sensor. In the presence of the ligand, this sensor showed a phosphate concentration-dependent increase in FRET efficiency. Shortening the composite linker region resulted in sensors having opposite ratio changes. Modifications of residues of the binding pocket of the Synechococcus. phosphate binding protein yielded sensors that covered a broad range of affinities for phosphate from low nanomolar to high millimolar. FLIPPi-200 $\mu$ and FLIPPi-30m were highly selective for phosphate compared to other phosphate containing molecules. When these sensors were synthesized in the cytosol of Chinese hamster $\mathrm{CHO}$ cells, they did not show a response to extracellular phosphate. After starvation, however, the FLIPPi-30m sensor responded with a reversible, concentration-dependent decrease in FRET efficiency. Accordingly, FLIPPi sensors can be used for real time monitoring of phosphate metabolism in living cells, tissues, or intact organisms, providing new bioimaging tools for monitoring metabolic dynamics. 


\title{
Posters: Nutrition
}

13. Cloning, in vitro characterization, and gene expression analysis of wheat and barley phytases

\author{
Dionisio Giuseppe, Holm P.B. and Brinch-Pedersen Henrik \\ Danish Institute of Agricultural Sciences, Research Centre Flakkebjerg, Department of Genetics \\ and Biotechnology, DK 4200 Slagelse, Denmark
}

During grain filling, a considerable reserve of phytic acid is produced and accumulated in the plant seed. Phytic acid is hydrolysed by the phytase enzymes, a heterogeneous class of phosphohydrolases, which group at least 3 classes of enzymes having different functional domains and belonging to different catalytic protein families: purple acid phosphatases, histidin acid phosphatases and $\beta$-propeller like phosphatases. Three isogenes of the histidin acid phosphatase from wheat and two from barley were cloned. The similarity with 3-phytases of fungal origin has been revealed at protein level by multiple alignment and high sequence similarities. After expression as $\mathrm{N}$ terminal HIS-tagged protein in E. coli, the protein was subjected to biochemical characterisation, confirming the activity as phytase by assaying the hydrolysis of phytic acid. After quantitative real-time RT-PCR it is clear, that the genes are highly expressed during grain filling and germination. However, the data further unravelled that the overall expression is concerted by differential tissue specific expressions of the isogenes. 


\section{Posters: Nutrition}

\section{Transcritional regulation in response to phosphate starvation in Arabidopsis thaliana}

Tom Hamborg Nielsen, Lena Nilsson, Renate Müller

Plant Biochemistry Laboratory, Dept. of Plant Biology, Royal Veterinary and Agricultural University, Thorvaldsensvej 40, DK-1871 Frederiksberg C, Denmark.

Phosphorus is an essential plant nutrient and a key player in growth and metabolism. Although phosphorus is abundant in the rhizosphere, the bioavailability of orthophosphate $(\mathrm{Pi})$ is low. Plants have evolved several molecular strategies to obtain adequate phosphate supply under limiting conditions.

We analyzed transcriptional regulation in response to phosphate starvation and/or sucrose treatment in Arabidopsis. The expression of selected marker genes was detected by RT-PCR, and global transcript profiles were analysed by DNA-microarrays. Many differentially expressed genes were identified for the two categories P-starvation and sucrose. Furthermore we can identify genes showing clear interaction between sugar- and phosphate sensing, demonstrating a close relationship between P-starvation response and sugar sensing. Interestingly some "classical" sugar sensed genes are also dependent on phosphate starvation. The genes showing these interactions cluster into three main groups with different response patterns. These clusters are clearly related to different functional group of genes. We are presently analysing the promoter elements characteristic for the gene regulation patterns.

In another approach to the area we analyse the role of a selected transcription factors (TFs). These belong to a small family of MYB-related TFs, where one factor, called PHR1, is known to mediate P-regulation of selected genes. We have both isolated T-tagged knock-out lines and produced over-expressor lines of the PHR1 factor. These lines show differences in Paccumulation, $\mathrm{P}$-distribution in the plant and gene expression and root/shoot ratio. Interestingly the plants over-expressing PHR1 also accumulate higher levels of $P$ in the leaves than wild type plants. Future studies will include a comprehensive analyse of the PHR1-related TF-family 


\title{
Posters: Nutrition
}

\section{Membrane sensors target transporters for ubiquitin-mediated degradation}

\author{
Morten H. H. Nørholm* and Barbara A. Halkier
}

Plant Biochemistry Laboratory, Center for Molecular Plant Physiology, The Royal Veterinary and

Agricultural University, Thorvaldsensvej 40, DK-1871 Frederiksberg C, Denmark

Membrane proteins play pivotal roles in animal and plant physiology. Genome sequencing projects have revealed that typically $15-20 \%$ of all genes encode membrane proteins. However, the percentage of drugs targeted against membrane proteins is much higher, emphasizing the importance of these proteins.

In recent years, a number of transport-inactive membrane transporter proteins have been proposed to function as sensors, although the underlying mechanism has remained elusive. Here, we show that the inactive Arabidopsis sucrose transporter SUC3 regulates active SUC homologs by facilitating their ubiquitination and degradation. Similarly, we show that the inactive mouse $\mathrm{Na}^{+}$ glucose co-transporter MmSGLT3b negatively regulates the activity of MmSGLT1. We find that the presence of a so-called PEST sequence is critical for the regulatory role of both SUC3 and MmSGLT3b. These observations suggest the presence of a universal, posttranslational mechanism for rapid and specific turnover of transport proteins via oligomerization with homologous sensors that target them for ubiquitin-mediated degradation. We propose that the mechanism represents a protein analogy to RNA interference.

Association of proteins to form dimers and high-order oligomers is not restricted to transport proteins, but is a common phenomenon among enzymes, ion channels, receptors and transcription factors. Accordingly, our hypothesis may be extended to include all types of proteins (including soluble ones) that dimerize. The findings may have potential in future design of artificial sensors for use in a protein knockout strategy, where specific proteins are targeted for rapid degradation, e.g. in gene therapy. 



\section{Posters: Diseases}




\title{
Posters: Diseases
}

\section{Classification of mRNA sequences from Fungal and Plant mixed sequence populations}

\author{
Jeppe Emmersen ${ }^{1}$, Stephen Rudd ${ }^{2}$ and Igor V. Tetko ${ }^{3}$
}

1:Aalborg University, Denmark. 2:Centre for Biotechnology, Finland. 3:Institute for Bioinformatics (MIPS), GSF, Germany.

Discovery of novel genes expressed during plant/pathogen interaction by EST sequencing of cDNA libraries results in a mixture of sequences from both plant and pathogen as the tissue from each organism is normally not separated before mRNA purification. The extent of the pathogen cDNA fraction varies with the amount of cells from the pathogen but is typically lower than the plant fraction, depending on the stage and severity of infection. EST sequences from such mixed cDNA populations are often deposited in GenBank without any attempt to purify and separate the EST sequences. Here we show that with a machine learning approach we can classify mRNA sequences from mixed plant and fungal mRNA. We used SVM (Support Vector Machine) based on triplet frequencies of mRNA sequences to obtain a separation performance above $90 \%$ for all plant/fungal pairs (15 dicots, 5 monocots and 10 fungi/oomycetes). Coding regions and UTR regions as well as 2-mers and 4-mers of mRNAs were also assayed in terms of separation power, but were found to classify below 3-mers of mRNA sequences. Although we used annotated mRNA (with respect to cds and UTR regions) sequences to verify the SVM method, contigs from assemblies of EST sequences were shown to perform at the same level of separation for plant/fungi. 


\title{
Posters: Diseases
}

\section{Characterization of three chitinase-encoding genes (cr-nag1, cr-ech58 and cr- ech37) from the fungus Clonostachys rosea (IK726).}

\section{Mojtaba Mamarabadi, Dan Funck Jensen and Mette Lübeck}

Plant Pathology Section, Department of Plant Biology, The Royal Veterinary and Agricultural University, Thorvaldsensvej 40, DK-1871 Frederiksberg C, Copenhagen, Denmark.

Keywords: mycoparasitism, gene, chitinase, Clonostachys rosea

\begin{abstract}
Clonostachys rosea is a widely distributed fungus that often acts as a parasite on other soil fungi. The mycoparasitic activity is thought to be correlated with the secretion of cell wall degrading enzymes, including chitinases. In this work, we identified and characterized three chitinase-encoding genes from the $C$. rosea strain IK726. Conserved motif regions among known exo- and endochitinase amino acid sequences from related fungi were used for design of degenerated primers, which were applied for PCR screening of $C$. rosea genomic DNA. The PCR products had strong similarity with known fungal $\mathrm{N}$-acetyl- $\beta$-D-glucosaminidases (exochitinases), and endochitinases and were used to obtain a $\mathrm{N}$-acetyl- $\beta$-D-glucosaminidase and two endochitinase genes including their promoter regions by a DNA walking strategy. The genes for the two endochitinases were named according to their predicted molecular mass. The cr-nag1, cr-ech58 and crech37 ORFs have a length of 1746 bp interrupted by two introns, 1802 bp interrupted by three introns and 1044 bp without any introns, respectively. The cr-nag1, cr-ech58 and cr-ech37 deduced proteins contain 20, 17 and 22 amino acids signal peptide, respectively. Southern analysis showed that all three genes are present as single copy genes in $C$. rosea. Enzymatic assays showed that the chitinase activity of $C$. rosea is specifically repressed in media containing glucose. RT-PCR analysis was performed to confirm that the genes are expressed and to study whether the expression pattern of each gene followed the general chitinase expression pattern found using enzymatic assays. The highest expression of $c r$-nag1 and cr-ech37 were found in media with Fusarium culmorum cell walls or chitin whereas almost no expression was detected in media with $1 \%$ glucose. The expression of $c r$-ech58 was low in all media tested and seems not to be regulated by glucose.

Future work will focus on studies of the role of these three chitinase encoding genes for C. rosea interaction with fungal pathogens by studying the expression of the genes using real time RT-PCR analysis.
\end{abstract}




\title{
Posters: Diseases
}

\section{Studies on expression of selected Trichoderma harzianum genes involved in biocontrol of plant diseases}

\author{
Mette Lübeck, Michaela Schiller and Dan Funck Jensen. Plant Pathology Section, \\ Department of Plant Biology, The Royal Veterinary and Agricultural University, \\ Thorvaldsensvej 40, DK-1871 Frederiksberg C, Copenhagen, Denmark.
}

This work is carried out as a part of the EU-project "TrichoEST": Functional genomics and proteomics of Trichoderma antagonist strains for industry and agriculture(QLK32002-02032), which started under the 5th Framework Programme "Quality of Life" December 1. 2002. The overall aims are to identify genes and gene products from Trichoderma spp. with biotechnology value, to assess their industrial potential and, to exploit and commercialize them in concert with EU biotechnology strategy. cDNA libraries from several Trichoderma strains belonging to different species are used to construct macro-arrays for use in expression studies with various purposes defined by the different partners in the consortium. The program also contains generation of 2-DE maps and identification of potentially interesting proteins, integrated bioinformatics analysis, in vitro and in vivo expression of selected cDNA clones and functional screening of in vitro expressed cDNA clones.

Our role in TrichoEST involve construction of cDNA libraries for two Trichoderma strains, the mycoparasite $T$. harzianum T3 and the mushroom pathogen $T$. aggressivum KNTP, cultivated in different conditions, and hybridization experiments (screening of macroarrays) using mRNA from time-course studies of the interaction of Trichoderma on plants with and without pathogens. Expressed cDNA libraries have been constructed from the two Trichoderma strains grown in different simulated mycoparasitic and antagonistic situations. From each cDNA library 1920 clones (ESTs) was sequenced.

Based on redundancy analysis, 767 unique ESTs were identified for T3 and used for construction of a macroarray. Using this macroarray, expression of genes in mycoparasitic interactions of T3 and the pathogen Pythium ultimum was studied in a time-course experiment. Interesting T3 ESTs up-regulated in the presence of $P$. ultimum have been identified and the genes have been partly identified using bioinformatics. Validation of selected differential expressed ESTs revealed by the macroarray analysis was performed by real-time RT-PCR analysis. Future work includes exploitation of the industrial potential of selected ESTs through the TrichoEST program and studies of the role of these genes for the biocontrol activities of T3. 


\title{
Posters: Diseases
}

\section{Lipo-oligosaccharide of Xanthomonas campestris triggers innate immune response in Arabidopsis thaliana possibly via different receptors.}

\author{
Mari-Anne Newman", Gitte Erbs", Tina Tandrup Jensen", Antonio Molinaro*, Alba Silipo*, \\ Luisa Sturiale ${ }^{\ddagger}$, J. Maxwell Dow ${ }^{\S}$, Rosa Lanzetta*, Michelangelo Parrilli \\ II Royal Veterinary and Agricultural University (KVL), Frederiksberg, Denmark.*, \\ Università di Napoli, Italy. ${ }^{\ddagger}$ Istituto per la Chimica e la Tecnologia dei Materiali Polimerici \\ - ICTMP - CNR, Catania, Italy. §BIOMERIT Research Centre, Cork, Ireland. \\ mari@kvl.dk
}

Lipopolysaccharides (LPSs) and lipooligosaccharides (LOSs) are major and vital components of the cell surface of Gram-negative bacteria that have diverse roles in bacterial pathogenesis of animals and plants. In plants, they may contribute to the exclusion of plant-derived antimicrobial compounds, hence promoting the ability of a bacterial pathogen to infect plants. Conversely, LPSs and LOSs can be recognized by plants to elicit or potentiate plant defense-related responses and cause prevention of the hypersensitive response (HR) induced by avirulent bacteria. Almost nothing is known of the molecular basis of the recognition processes that trigger these plant responses. Here we address this issue through the structural determination of the LOS of Xanthomonas campestris pv. campestris strain 8004 and examine the effects of this molecule and fragments obtained from it by chemical treatments on the prevention of HR and the induction of the defense-related gene PR1 and PR2 in Arabidopsis thaliana. LOS and the lipid $A$ and core oligosaccharides derived from it were all able to prevent the HR in Arabidopsis thaliana caused by avirulent bacteria and to induce PR1 and PR2 transcript accumulation. However although LOS induced PR1 and PR2 transcript accumulation in two temporal phases, the core oligosaccharide induced only the earlier phase and lipid $A$ only the later phase. These findings indicate that plant cells can recognize lipid $A$ and core oligosaccharide structures within LPS to trigger defensive cellular responses possibly via different receptors. 


\title{
Posters: Diseases
}

\section{Virus Induced Gene Silencing in a Legume Species}

\author{
Gabriela D. Constantin", Mette Grønlund ${ }^{\star}$, Britta N. Krath ${ }^{*}$, Stuart A MacFarlane*, \\ I. Elisabeth Johansen ${ }^{*}$ and Ole S. Lund \\ *Department of Plant Biology, Danish Institute of Agricultural Sciences, Thorvaldsensvej \\ 40, DK-1871 Frederiksberg C, Denmark. \\ ${ }^{*}$ Scottish Crop Research Institute, Invergowrie, Dundee, Scotland DD2 5DA
}

Viruses induce a defence system in plants, which targets the viral genomic RNA for degradation. Insertion of a fragment of a host gene into the virus genome results in degradation of the recombinant virus as well as mRNA of host genes with high sequence identity to the inserted fragment. This phenomenon is known as Virus Induced Gene Silencing (VIGS) and has been shown to be a powerful tool for functional genomics in different species $(3,5)$. As an "easy to use" tool, VIGS can provide information about candidate genes involved in important pathways, assigning phenotypes and confirming their putative functions.

We have tested the possibility of using this technology in legumes. As a model system we have chosen pea (Pisum sativum) and the tobravirus, Pea early-browning virus (PEBV). Infectious cDNA of PEBV has previously been cloned and engineered to express foreign genes from RNA-2 (4). DNA fragments of three selected reference target genes were inserted as part of the RNA-2. The genes targeted were: Phytoene desaturase, Unifoliata, and Korrigan. 14-28 dpi the plants exhibited phenotypes similar to those previously reported for the respective mutants (2). Ongoing experiments are focusing on evaluating the applicability of the system for root - symbiotic studies using Nodule inception gene as a reference target gene (1).

(1) Borisov, et al., (2003) Plant Physiol. 131(3): 1009-17; (2) Constantin et al., (2004) Plant J. 40: 622-63; (3) Liu et al., (2002) Plant J. 31(6): 777-86; (4) MacFarlane and Popovich . (2000) Virology 267(1): 29-35; (5) Ratcliff et al., (2001) Plant J. 20(8): 206978. 



\section{Posters: Breeding}




\title{
Posters: Breeding
}

\section{Molecular Analysis of Sugarcane Mosaic Virus (SCMV) Resistance in Maize}

\author{
Christina Ingvardsen1, Yongzhong Xing1, Shi Chun2, Thomas Lübberstedt1 \\ 1Department of Genetics and Biotechnology, Research Centre Flakkebjerg, 4200 \\ Slagelse, Denmark
}

\begin{abstract}
2Lehrstuhl für Pflanzenbau und Pflanzenzüchtung, Technische Universität München, Germany
\end{abstract}

The potyvirus sugarcane mosaic virus (SCMV) is an important pathogen of maize (Zea mays L.), causing chlorosis, stunting and serious yield loss in susceptible cultivars. Three major resistance genes confer resistance to SCMV, one gene located on chromosomes 3 and two genes closely linked on chromosome 6 . However, the molecular mechanisms underlying the establishment and progression of SCMV infection in maize are poorly understood.

A near-isogenic line, $\mathrm{F} 7+$, carrying the resistance regions from chromosome 3 (Scmv2) and 6 (Scmv1a and 1b) in a susceptible background was developed. Based on F7+, nine isogenic genotypes segregating in these two regions were developed. Testing the nine genotypes for response to SCMV infection showed that the Scmv1 and Scmv2 locus interact epistatically and that one resistance region alone was not sufficient for complete resistance against SCMV. When the resistant allele is fixed at either the Scmv1 or Scmv2 locus, the susceptible homozygote at the other locus is easily distinguishable from the genotypes carrying one or two resistance alleles. Based on these findings we are currently in the process of map based gene isolation using large $F_{2}$ populations for each of both genome regions. A BAC library has been constructed from the resistant inbred line FAP1360A for physical mapping of the Scmv1 and Scmv2 loci and isolation of the causative genes. This BAC library has been screened for NBS-LRR resistance candidate genes located in the Scmv1 region.

In order to identify additional candidate genes, we combined suppression subtractive hybridization (SSH) and macroarray hybridization to identify genes differently expressed in the near isogenic line (NIL) pair F7+ (SCMV resistant) and F7 (susceptible).

Altogether, 302 differentially expressed genes were identified. Among the mapped genes, 31\% (18 out of 58) were located within the Scmv2 and Scmv1 loci on chromosomes 3 and 6 , respectively. 


\title{
Posters: Breeding
}

\section{Characterization of genes associated with feed quality in maize}

\author{
Andersen, Jeppe Reitan; Asp, Torben; Lübberstedt, Thomas \\ Danish Institute of Agricultural Sciences, Department of Genetics and Biotechnology, \\ Research Centre Flakkebjerg, 4200 Slagelse, Denmark.
}

Maize (Zea mays L.) has become a major fodder crop in Danish dairy farming, now being grown on one third of the total area used for fodder crops. During recent decades, breeding efforts have lead to a substantial increase in whole plant yield. However, during the same period of time there has been a steady decrease in cell wall digestibility, and, consequently, in feeding value of elite maize hybrids. Cell wall digestibility is influenced by both lignin content and lignin structure. Thus, promising candidate genes for improving digestibility of silage maize are genes involved in the lignin biosynthetic pathway.

Lignin is formed by the polymerization of monolignols, a process catalyzed by peroxidases and laccases. The laccase gene family is well conserved across species, facilitating Arabidopsis as a convenient model system. We have identified 17 members of the laccase gene family in Arabidopsis and knock-out mutants have been obtained. Mutants are being phenotypically characterized and screened for in vitro digestibility. The most promising candidate genes for digestibility will subsequently be cloned and characterized in maize.

In addition, a number of genes involved in the biosynthesis of monolignols in maize have been sequenced and characterized. Two of these genes, PAL and COMT, have been tested for associations with different quality-related traits in lines currently employed in European silage maize breeding. While levels of linkage disequilibrium differ at those two loci, indicating differences in selection pressure, individual polymorphisms within both genes are associated with digestibility. 


\section{Posters: Breeding}

\section{Foliage late blight resistance QTLs in clones of Solanum tuberosum and S. vernei}

Kirsten K. Sørensen ${ }^{1}$, Marianne H. Madsen ${ }^{1}$, Hanne Grethe Kirk ${ }^{2}$ and Dorothy K. Madsen ${ }^{1}$

${ }^{1}$ Danish Institute of Agricultural Sciences, Research Centre Foulum, P.O. Box 50, DK8830 Tjele, Denmark

${ }^{2}$ Danish Potato Breeding Foundation, Grindstedvej 55, DK-7184 Vandel, Denmark

The cultivated potato (Solanum tuberosum) is the fourth most important food crop worldwide. The major disease of potato is late blight, caused by Phytophthora infestans. It results in severe yield losses or necessitates the use of large amounts of fungicides, which is expensive and associated with environmental and health risks. Use of late blight resistant varieties is the most desirable strategy to control the disease. Wild species are donors of resistance and crossing with such unadapted material is often used. However, conventional potato breeding is a lengthy process and DNA-markers and markerassisted selection (MAS) might be used as a supplement. The wild potato species $\mathrm{S}$. vernei is a source of valuable resistance genes to potato cyst nematodes and if it contains interesting resistance genes to P. infestans it might be further attractive in resistance breeding programmes.

In the present research two diploid $F_{1}$ populations designated HGIHJS and HGG, originating from a cross between S. vernei (accession no. 3504) and two clones of S. tuberosum (90-HAE-42 and 89-0-08-21) were evaluated for foliage late blight infestation in field trials, and quantitative trait locus (QTL) mapping was performed.

Results indicated that resistance in this clone of $\mathrm{S}$. vernei was of a quantitative inherited type. Major QTLs for foliage late blight resistance were identified on chromosomes $\mathrm{VI}$, VIII, IX (significant) and VII (putative) of S. vernei. In addition a significant and a putative QTL was detected on chromosomes IV and V, respectively, of S. tuberosum. Some of these QTLs might be useful in MAS. 


\title{
Posters: Breeding
}

\section{Genetics of Symbiosis in Lotus japonicus: Recombinant Inbred Lines, Comparative Genetic Maps and Map Position of 37 Symbiotic Loci.}

\author{
Niels Sandal*, Keisuke Yokota*, Leïla Tirichine*, Thomas Rørby Petersen*, Paloma \\ Rueda Romero*, Simona Radutoiu*, Lene Krusell*, Lene H. Madsen*, Esben Madsen*, \\ Jens Stougaard* and the International Lotus Symbiotic Community
}

* Department of Molecular Biology, University of Aarhus, Gustav Wieds Vej 10, 8000 Aarhus C

Development of molecular tools for the analysis of the plant genetic contribution to rhizobial and mycorrhizal symbiosis has provided major advances in our understanding of plant-microbe interactions and several key symbiotic genes have been identified and characterised. In order to increase the efficiency of genetic analysis in the model legume Lotus japonicus, we present a selection of improved genetic tools.

The two genetic linkage maps previously developed from an interspecific cross between L. japonicus Gifu x Lotus filicaulis and an intraspecific cross between two ecotypes $L$. japonicus Gifu x L. japonicus MG-20, were aligned through a set of anchor markers.

Additional genetic resolution and stabilised mapping populations were obtained in recombinant inbred lines derived by a single seed descent from the two populations.

Combining resources from the Lotus community, map positions of a large collection of symbiotic loci known from mutants are provided together with alleles and closely linked molecular markers. Altogether this establishes a common genetic resource for Lotus. A web-based version will enable this resource to be curated and updated regularly.

Reference: Sandal et al., 2006 MPMI 17, 80-91. 


\section{Posters: Breeding}

\section{Development of legume anchor markers A tool for genetic mapping and comparative genomics driven by bioinformatics}

Birgit Kristine Hougaard1, Lene Heegaard Madsen1, Jacob Fredslund2, Leif Schauser2, Anna Marie

Nielsen1, Niels Sandal1, David J. Bertioli3, Joe Tohme4, Mathew Blair4 and Jens Stougaard1,

1 Laboratory of Gene Expression, Department of Molecular Biology, University of Aarhus, GustavWieds Vej 10, DK-8000 Aarhus C, Denmark

2 Bioinformatics Research Center, University of Aarhus, Hoegh-Guldbergsgade 10, DK8000 Aarhus C, Denmark

3 Universidade Católica de Brasília, SGAN 916, CEP 70.790-160 Brasilia, DF, Brazil

4 Biotechnology Research Unit, CIAT, Apartado Aéro 6713, Cali, Colombia

Comparative genetic mapping allow the transfer of genetic information from one species to another. In the legume family the genomes of a few species (e.g. Lotus japonicus) are well-characterised, and genome information from these could make an important contribution to breeding programs in crop legumes like groundnut and common bean, which have less well-characterised genomes. "Anchor" markers, defining unique loci on genetic linkage maps of multiple species, are gene based and need to possess a number of features that alltogether make them relatively sparse. To identify potential anchor marker sequences more efficiently and speed up the process of primer design, we have established an automated bioinformatic pipeline that suggest intron-spanning primers (1) for use throughout any given plant family.Ninety-two pipe-line generated, legume based primer sets have been tested in both bean and the distantly related groundnut, and we now have a total of 81 anchor markers in bean and 99 anchor markers in groundnut. The preliminary results on synteny between common bean and $\mathrm{L}$. japonicus look very promising.

(1) Fredslund, J., L. Schauser, et al. (2005). "PriFi: using a multiple alignment of related sequences to find primers for amplification of homologs. "Nucleic Acids Res. 33 (Web Server issue): W516-20 


\section{Posters: Breeding}

\section{Identification and characterisation of LORE1 and LORE2, active retrotransposons in model legume Lotus japonicus}

Eigo Fukai, Lene Heegaard Madsen, Simona Radutoiu, Alicja Dobrowolska, Christopher Karl Yost, Niels Sandal, Leif Schauser, Jens Stougaard

Laboratory of Gene Expression, Department of Molecular Biology, University of Aarhus

We had isolated five independent symbiotic (sym) mutants of Lotus japonicus ecotype Gifu, having unknown insertions in the responsible genes. From sequence analysis, it was revealed that all of the 5 insertions were endogenous Ty3-gypsy retrotoransposons in Lotus. They were classified into 2 families, designated as LORE1 and LORE2 (Lotus Retrotransposon 1 and 2), from their nucleotide sequences.

LORE1 was found as insertions in responsible genes of three sym mutants, nin-7, symrk2-1, and nup133-3. Nucleotide sequences of those three LORE1 copies were $100 \%$ identical each other. The number of native copies of LORE1 in Gifu was estimated at nine. Only one of the native copies had sequence identical to the element found in sym genes suggesting that only one copy is active (transposable). Transcripts of LORE1 were detected in all tissues investigated, including callus.

LORE2 was found as insertions in the responsible genes of two sym mutants, symrk cac41.5 and nfr5-2. LORE2 isolated from symrk cac41.5, had additional 117-bp stretch in its sequence compared with that of nfr5-2, suggesting that at least two independent copies of LORE2 are active in Gifu. LORE2 was transcribed in all tissues investigated, including callus. We estimate that the number of LORE2 copies in Gifu is at least fifteen.

To establish retrotransposon-tagging system in Lotus using LORE1,2, further characterisation of those retrotransposons is now proceeding. The data from those investigations will also give us new insights about mechanisms regulating activity of Ty3gypsy retrotransposons in plant. 


\title{
Posters: Breeding
}

\section{Resistance gene analogues and QTL analyses in Lolium perenne}

\author{
Britt Schejbel, Yongzhong Xing, Thomas Lübberstedt
}

Danish Institute of Agricultural Science, Research Centre Flakkebjerg

To facilitate the breeding of perennial ryegrass and ultimately produce functional markers, resistance gene analogues (RGAs) have been identified and mapped in a Lolium perenne $\mathrm{F}_{2}$ mapping population ( $\mathrm{VrnA}$ ). The mapping population was originally produced from an Italian variety "Veyo" and a Danish ecotype "Falster" to study vernalisation response. This mapping population has been mapped with SSR, AFLP and CAPS markers to a total size of 330cM. Based on homology to known resistance genes from other monocot species RGAs have been isolated and sequenced in the grandparents of the mapping population, CAPS markers have been developed and the RGAs have been mapped. Infection studies with crown rust (Puccinia coronata) on leaf segments and in field experiments have been used to identify QTLs for rust resistance in the mapping population. In this study one RGA cosegregated with a QTL for rust resistance on linkage group 6 with a lod score of 3.02 which is significant on the chromosome level. Another QTL analysis will be performed on the interaction between perennial ryegrass and powdery mildew in the aim to discover RGAs involved in the resistance against powdery mildew. Subsequently the RGAs identified that cosegregate with QTLs for resistance will be further analysed in expression studies. This project is funded by the EU framework $V$ as part of the GRASP project on development of ryegrass allele specific markers for sustainable grassland improvement www.graspeuv.dk. 


\title{
Posters: Breeding
}

\section{Genetic Mapping and cultivar identification in spinach (Spinacia Oleracea L.).}

\author{
Jabar Zaman Khan Khattak, Jørgen Lindskrog Christiansen, Anna Maria Torp, \& Sven \\ Bode Andersen
}

The Royal Veterinary and Agricultural University, Department of Agricultural Sciences,

Laboratory of Plant and Soil Science, Thorvaldsensvej 40, DK-1871 Frederiksberg C, Copenhagen, Denmark Phone: +45 352834 36, Fax: +45 352834 60, E-mail: jzk@kvl.dk

Spinach (Spinacia oleracea L.) belongs to the Chenopodiaceae family and natural populations of the species show distinct male and female plants. Spinach is a major vegetable crop used for fresh market products consumed after a light cooking, or it is processed to deep frozen products. Danish farmers produce a major part of the world's commercial spinach seed every year. A good deal of this seed is hybrid produced through intercrossing between two inbreds, both of which are modified in their sex expression to control pollination.

Not much molecular markers or mapping work has been published for spinach crops. In the present work molecular markers such as AFLP and SSRs were assigned to spinach. Two major aspects have been studied with the markers: 1) genetic mapping along with sex determination and 2) analysis of different spinach cultivars form different parts of the world for the identification purposes with the help of microsatellite markers.

A genetic map of spinach was constructed comprising 110 markers (101 AFLP and 9 microsatellite) scored in a classical back cross population to form a map with a total length of $585 \mathrm{cM}$ divided into seven linkage groups. The linkage map was constructed with LOD 3.5, but was quite stable with seven linkage groups remaining until LOD 7.0. Gender segregated 1 male to 1 female in the mapping population and was mapped to a small area of one linkage group with a distance of $1.9 \mathrm{cM}$ to the nearest microsatellite marker termed SO4. Literature on sex determination in spinach is divided since some studies have argued the existence of regular $X Y$ sex chromosomes like in mammals. This study with genetic markers does not indicate heteromorphic sex chromosomes in spinach, because the chromosome pair harboring the sex determining factor apparently recombines along their full length.

The cultivar identification study used only SSR markers and included identified 33 different hybrid spinach cultivars imported from seven different breeding stations all over the world. The analysis showed successful separation of all cultivars and the marker system worked efficiently. Relatively high gene diversity was indicated in spinach plant material as 10 SSR primers showed average diversity per marker off 0.5 or above. A minimum of six SSR primer pairs were needed to discriminate all 33 cultivars of spinach in the study. European and Asian types of spinach were well discriminated into the clusters. Microsatellite markers apparent are very useful for cultivar identification of spinach and they may also be used for seed purity control. 


\title{
Posters: Breeding
}

\section{Allergenicity of different plant organs from various legumes using histamine release assay}

\author{
Jensen, L.B. ${ }^{1,2}$, Skov, P.S. ${ }^{1}$, Torp, A.M. ${ }^{2}$, Poulsen, L.K. ${ }^{1}$, Bindslev-Jensen, C. ${ }^{3}$, \\ Andersen, S.B. ${ }^{2}$ \\ ${ }^{1}$ Laboratory of Medical Allergology, Allergy Clinic, National University Hospital, \\ Copenhagen \\ ${ }^{2}$ Department of Agricultural Sciences, Royal Veterinary and Agricultural University, \\ Copenhagen, Denmark \\ ${ }^{3}$ Allergy Centre, Odense University Hospital, Odense
}

Aim: Consumption of fresh bean sprouts in e.g salads may pose a potential risk to peanut allergic patients since the proteins are not denatured before consumption and thus might induce a severe allergic reaction. The aim of the present study was to investigate the possible allergenicity of different legume species and organs towards peanut allergic patients.

Materials and methods: Sprouts were prepared from 7 different legumes; peanut, soybean, green pea, blue lupine, alfalfa, mung bean, and broad bean. Protein extracts were prepared from fresh seeds, cotyledons, and hypocotyls/epicotyls. Protein content was measured using the Biorad method. Protein extracts were tested for biological activity using passively sensitized blood basophils. Sera from three different peanut allergic patients and one non-peanut allergic patient were used to test reactivity of the legume extracts. The passively sensitized cells were incubated with 6 different dilutions of the legume extracts. The amount of histamine released from the cells was quantified using the glass-microfiber method (RefLab). The amount of released histamine was expressed as a percentage of the total histamine content of the cells.

Results: All 3 patients reacted to the three peanut plant organs. In addition, reactions were observed to plant organs from all tested legumes. Even hypocotyls/epicotyls induced histamine release. The highest release was observed for peanut and pea, and the lowest for broad bean.

Conclusions: The reactions observed from the basophils after stimulation with extracts indicate that the legume proteins hold partially identical epitopes that are recognized by patient antibodies. 



\section{Posters: Systems Biology}




\title{
Posters: Systems Biology
}

\section{Protein oxidation in plant mitochondria}

\author{
Ian Max Møller \\ Department of Agricultural Sciences, KVL, Thorvaldsensvej 40, 1871 \\ Frederiksberg C
}

The mitochondrion is the major site of production of Reactive Oxygen Species (ROS) in plant cells in darkness. ROS can cause damage to proteins, lipids and DNA. We are developing methods to characterize protein oxidation to understand the consequences of oxidative stress.

A matrix fraction was isolated from rice leaf mitochondria. Oxidised proteins were tagged with dinitrophenylhydrazine (DNP), which forms a covalent bond with carbonyl groups. The DNP-tagged proteins were immunoprecipitated using antiDNP antibodies and digested with trypsin. The peptides were separated by ion exchange chromatography followed by reverse phase chromatography and analysed online by MS/MS. Twenty oxidised proteins were oxidised in a control sample and a further 31 proteins were oxidised in an in vitro oxidised sample. We conclude that a number of proteins are oxidised in vivo and further identify a group of proteins that are particularly susceptible to mild oxidation.

The formation of $\mathrm{N}$-formylkynurenine by dioxygenation of tryptophan was detected in peptides from rice leaf and potato tuber mitochondria. Proteins were separated by two-dimensional gel electrophoresis and identified by MS/MS. NFormylkynurenine was detected in 29 peptides representing 17 different proteins. With one exception, the oxidation-sensitive aconitase, all of these proteins were either redox active themselves or subunits in redox-active enzyme complexes. The same site was modified in (i) several adjacent spots containing the P-protein of the glycine decarboxylase complex, (ii) two different isoforms of the mitochondrial processing peptidase in complex III and (iii) the same tryptophan residues in Mn-superoxide dismutase in both types of mitochondria. This indicates that Trp oxidation is a selective process. 


\section{Posters: Systems Biology}

\section{Transcript profiling of potato tuber development by LongSAGE.}

Annabeth Laursen Høgh, Jeppe Emmersen and Kåre Lehmann Nielsen Section of Biotechnology, Aalborg University, Denmark.

Solanum tuberosum (potato) is the fourth major crop worldwide and used for food, feed and biotechnological applications. To fully realize the biosynthetic potential for production of starch, protein and metabolites, we conducted an extensive quantitative profiling of the expressed genes of the three different developmental stages of the potato tuber cv. Kuras by Serial Analysis of Gene Expression (SAGE). We have conducted a LongSAGE transcript profiling of approximately 50,000 tags from each of 4 developmental stages of potato tubers, 8 week old plants (mini tuber), tubers harvested at the end of flowering (mature tuber), tubers stored for 30 days (dormant) and from tuber tissue just below the shoot of a sprouting tuber. Pair wise comparisons of SAGE libraries were conducted, and significantly up or down regulated genes were identified using the Z-test at $98 \%$ confidence. In general many changes are observed, indicating that the tuber is not merely an inactive storage organ, but indeed a metabolically active and dynamically regulated plant organ. Interesting observations with regard to transcripts encoding storage proteins, proteases and their inhibitors and metallothioneins will be discussed. 


\title{
Posters: Systems Biology
}

\section{Purification and Characterization of Isatin Hydrolase from Mesorhizobium loti and Identification of the Gene Encoding the Enzyme.}

\author{
Bjarne U. Jochimsen*, Dorothy K. Madsen, Jan J. Enghild and Jens Stougaard \\ Department of Molecular Biology, University of Aarhus, DK-8000 Aarhus C, \\ Denmark
}

The enzyme isatin hydrolase was purified to near homogeneity from the strain NZP 2235 of Mesorhizobium loti, the microsymbiont of Lotus species. Purification involved just a few steps: hydrophobic interaction chromatography with PhenylSepharose, DEAE-Sephadex anion chromatography followed by analytic gelfiltration on a Superose-12 column. The enzyme has high affinity for isatin, $\mathrm{Km}$ being $\sim 20 \quad M$. The molecular mass in the presence of SDS was estimated to $\sim 32 \mathrm{kDa}$ and gelfiltration revealed elution as a $\sim 31 \mathrm{kDa}$ protein indicating a monomeric structure of the native enzyme. The enzyme require $\mathrm{Mn}^{2+}$ for activity. The protein band visible on a SDS polyacrylamide gel was cut out, incubated with trypsin and the resulting peptides analyzed by mass spectrometry. Fourteen peptide fragments (representing a $68 \%$ coverage) matched the theoretical fragments deduced from the hypothetical protein mlr5444 from Mesorhizobium loti MAFF303099. The gene encode a protein with a calculated mass of $28.3 \mathrm{kDa}$ and a conserved motif: HXGTHXDXPXH, thought to be the catalytic site of cyclases and of metal ion dependent hydrolases. A blast search using the amino acid sequence revealed only a few species of bacteria with sufficient homology (above 50\% identity) to warrant that the enzyme might be present in these species. Among those were: Bradyrhizobium japonicum (the symbiont of soybean), Ralstonia solanacearum (a plant pathogen) and an ocean living bacterium Silicibacter pomeroyi. The presence of isatin hydrolase in these species was verified by enzymatic assay.

Isatin hydrolase has been recognized as an enzyme involved in degradation of indole-3-acetic acid (IAA) in free living Bradyrhizobium japonicum, able to use IAA as a carbon- and nitrogen source. The occurrence of isatin hydrolase in Mesorhizobium loti is an enigma, since this bacterium is unable to catabolize IAA and unable to gain any energy from hydrolyzing isatin into isatinate. The DNA encoding mlr5444 was amplified by PCR and cloned into E. coli in order to obtain sufficient recombinant protein for further biochemical studies, that might reveal a possible role of this enzyme in Mesorhizobium. 


\section{Posters: Systems Biology}

\section{In vivo analysis of Arabidopsis High Mobility Group proteins}

Dorte Launholt ${ }_{i}^{1}$ Thomas Merkle ${ }^{2}$; Klaus D Grasser $^{1}$

(1) Department of Life Sciences - Section of Biotechnology, Aalborg University, DK-9000 Aalborg.

(2) Department of Genome research Center of Biotechnology, University of Bielefeld, D-33594 Bielefeld.

The High Mobility Group (HMG) proteins are a heterogeneous group of small and abundant non-histone proteins present in the cell nuclei of all eukaryotes. The HMG proteins interact with the eukaryotic DNA and upon binding the proteins modulate the structure of the DNA. They thereby facilitate the binding of e.g. transcription factors to the DNA that then initiate the transcription of genes. The HMG proteins are therefore very important for the function of the organism. Although there have been reports indicating an involvement of HMG proteins in replication, transcription and nucleosome assembly, the exact cellular function of the proteins is still largely unknown in plants. The main focus of the project is therefore to use various methods to analyse the protein functions using Arabidopsis thaliana as the model plant. The results presented here are based on two primary approaches: (1) Analyses of $h m g$ gene promoter activity using hmg-promoter-reporter gene fusion, and (2) determination of the cellular localisation and of the nuclear localisation sequences using HMG-GFP fusion proteins.

Grasser, K.D. (2003) Chromatin-associated HMGA and HMGB proteins: versatile co-regulators of DNA-dependent processes. Plant Mol. Biol. 53, 281-295. 


\title{
Posters: Systems Biology
}

\section{Novel HMG-box containing proteins from Arabidopsis thaliana}

\author{
Marion Grasser, Anne Lentz, Jacek Lichota, Thomas Merkle ${ }^{\#}$ and Klaus D. \\ Grasser \\ Department of Life Sciences, Aalborg University Sohngaardsholmsvej 49 DK- \\ 9000 Aalborg, Denmark, and ${ }^{\#}$ Department of Genome research Center of \\ Biotechnology, University of Bielefeld, D-33594 Bielefeld \\ kdg@bio.auc.dk
}

The high mobility group (HMG) proteins of the HMGB family are chromatinassociated proteins. As a common feature they contain a so-called HMG-box DNA-binding domain of $\sim 75$ amino acid residues. HMGB proteins act as architectural factors in various nucleoprotein structures, which regulate DNAdependent processes such as transcription and recombination. Database analyses revealed that in addition to the previously identified HMGB1-HMGB6 proteins, the Arabidopsis genome encodes at least two other family members (AGI loci At2g34450 and At5g23405) having the typical overall structure of a central HMG-box DNA binding domain, which is flanked by basic and acidic regions. These novel HMGB-type proteins display some structural differences, when compared to HMGB1-HMGB6. Therefore, the two proteins were analysed to determine, whether they share typical functional properties with the previously characterised HMGB proteins of maize and Arabidopsis. Subcellular localisation experiments demonstrate that the At2g34450 protein is a nuclear protein, whereas the At5g23405 protein is found in the cytoplasm. According to CD measurements, the HMG-box domains of both proteins have an a-helical structure, as expected from the HMG-box structure. The At2g34450 protein interacts with linear DNA and binds structure-specifically to DNA minicircles, whereas the At5g23405 protein does not interact with DNA at all. In T4 DNA ligase-mediated ligation experiments with short DNA fragments, At2g34450 can facilitate the formation of linear oligomers, but it does not promote the formation of DNA minicircles. Therefore, the At2g34450 protein shares several features with HMGB proteins, whereas the At5g23405 protein (despite stiking sequence similarity) has different characteristics. In summary our data demonstrate (i) that plant HMGB-type proteins are functionally variable and (ii) that it is difficult to predict HMG-box function solely based on sequence similarity.

Grasser, K.D. (2003) Chromatin-associated HMGA and HMGB proteins: versatile co-regulators of DNA-dependent processes. Plant Mol. Biol. 53, 281-295.

Grasser, K.D., Grill, S., Duroux, M., Launholt, D., Thomsen, M.S., Nielsen, B.V., Nielsen, H.K. and Merkle, T. (2004) HMGB6 from Arabidopsis thaliana specifies a novel type of plant chromosomal HMGB protein. Biochemistry $43,1309-1314$. 


\title{
Posters: Systems Biology
}

\section{The Arabidopsis FACT chromatin remodelling complex}

\author{
Jesper T. Grønlund, Andreas Houben" and Klaus D. Grasser \\ Department of Life Sciences, Aalborg University, Sohngaardsholmsvej 49, \\ DK-9000 Aalborg, and "IPK Gatersleben, Germany \\ kdg@bio.aau.dk
}

The FACT (facilitates chromatin transcription) complex consists of the SSRP1 and Spt16 proteins, and facilitates transcript elongation in chromatin by remodelling nucleosomes in the path of RNA polymerase II without requirement for ATP-hydrolysis. In Arabidopsis SSRP1 and Spt16 are co-expressed in early embryo development, and in seedlings the proteins can be found in the majority of cell types except in terminally differentiated cells. Within the cell nucleus SSRP1 and Spt16 localise to euchromatin, but not to heterochromatic chromocenters. Using ChIP, the Arabidopsis FACT complex was found to associate with actively transcribed genes in a transcription-dependent manner. FACT associates with the entire transcribed region of the genes, consistent with a role in transcript elongation. Analysis of Arabidopsis lines carrying T-DNA insertions in the gene encoding SSRP1 indicates that SSRP1 is essential for plant development. A line with an insertion towards the 3 '-end of the coding sequence is viable, but it displays various developmental defects.

Duroux, M., Houben, A., Ruzicka, K., Friml, J. and Grasser, K.D. (2004) The chromatin remodelling complex FACT associates with actively transcribed regions of the Arabidopsis genome. Plant J. 40, 660-771.

Grasser, K.D. (2005) Emerging role for transcript elongation in plant development. Trends Plant Sci., 10, 484-490. 


\section{Posters: Systems Biology}

\section{The TCX gene family in Arabidopsis thaliana}

Randi G. Algreen-Petersen, Stig Uggerhøj Andersen and Erik Østergaard Jensen Laboratory for Gene Expression, Department of Molecular Biology, University of Aarhus.

A novel DNA binding protein (GmCPP1) was previously identified in Glycine max. The protein was located in the nucleus and contained two conserved cysteine-rich regions. These motifs are part of the DNA binding region and with a short conserved sequence in between constitute the CRC domain. Proteins containing this domain are called TCX proteins (Andersen, 2004 and Cvitanich et al., 2000). The CRC domain is highly conserved across eukaryotic species and thus the TCX proteins were chosen for further investigation. Based on sequence homology, outside the CRC domain, the tcx genes can be divided into four subtypes. Type 1 and 2 are two distinct groups of TCX proteins in plants.

To identify the function of the TCX proteins reverse genetics was employed on the model legume Lotus japonicus. However, all available reverse genetic methods for down-regulationg the expression of the LjCPP gene in $L$. japonicus failed.

Subsequently, Arabidopsis thaliana was chosen for further studies, because morfological alterations of mutants in the type 1 tcx gene AtTSO1 already was discovered. Interestingly previous studies have demonstrated that tcx gene expression was associated to reproductive tissues (Liu et al., 1997, Hauser et al., 1998, Song et al., 2000, Hauser et al., 2000, Andersen et al., 2004) and maybe acting as part of a multiproteincomplex (Korenjak et al., 2005). We have identified a number of $A$. thaliana insertion mutants in the tcx genes, and when not available complemented with RNAi constructs. Selected phenotypes of the floral organs will be presented.

Andersen SU (2004) Characterization of the TCX protein family, Ph.D Thesis, Århus university.

Cvitanich C, Pallisgaard N, Nielsen KA, Chemnitz Hansen A, Larsen K, PihakaskiMaunsbach K, Marcker KA, Østergaard Jensen E (2000) CPP1, a DNA-binding protein involved in the expression of a soybean leghemoglobin c3 gene. PNAS 97: 8163-8168. Hauser BA, Villanueva JM and Gasser CS (1998) Arabidopsis TSO1 regulates directional processes in cells during floral organogenesis. Genetics 150: 411-423. Hauser BA, He JQ, Park SO and Gasser CS (2000) TSO1 is a novel protein that modulates cytokinesis and cell expansion in Arabidopsis. Development 127: 2219-2226. Korenjak M, Taylor-Harding B, Binné UK, Satterlee JS, Stevaux O, Aasland R, WhiteCooper H, Dyson N and Brehm A (2004) Native E2F/RBF complexes contain Mybinteractiong proteins and repress transcription of developmentally controlled E2F target genes. Cell 119: 181-193.

Liu Z, Running MP and Meyerowitz EM (1997) TSO1 functions in cell division during Arabidopsis flower development. Development 124: 665-672.

Song J-Y, Leung T, Ehler TK, Wang C and Liu Z (2000) Regulation of meristem organization and cell division by TSO1, an Arabidopsis gene with cysteine-rich repeats. Development 127: 2207-2217. 


\title{
Posters: Systems Biology
}

\section{Cereal Proteomics: Protein appearance pattern and transcript profiling in the barley aleurone layer}

\author{
Azar Shahpiri, Christine Finnie, Birte Svensson \\ Biochemistry and Nutrition Group, BioCentrum, Building 224, Søltofts Plads, \\ Technical University of Denmark, DK- 2800 Kgs. Lyngby, Denmark
}

The hormone-mediated control of seed germination in cereal seeds involves a combination of anatomic changes, gene expression and protein synthesis in the aleurone layer. Separation of the aleurone layer from other tissues and maintaining it in a culture medium provides a suitable well defined system for studying effects of hormones on gene expression in the aleurone layer. western blotting using specific primary antibodies enabled assessment of levels of $\alpha$ amylase, limit dextrinase (LD), a-amylase/subtilisin inhibitor (BASI) and thioredoxin $h$ (HvTrxh) in both cultured aleurone layers and the culture supernatants as derived after the administration of either gibberellic acid (GA) or abscisic acid (ABA) at different time points. 2D western blots ( $\mathrm{pH}$ range 3-7) of aleurone extracts revealed that each of these proteins is present in more than one spot and that the appearance pattern of these spots can be changed in response to hormonal treatment. Further work however is required to determine whether these spots contain different isoforms or if they result from post translational modifications.

In order to correlate mRNA and protein levels, gene expression analysis is carried out in parallel by the aid of northern blotting. These experiments form the basis for studying the change in aleurone layer transcriptomes and proteomes in response to $G A$ and $A B A$. 


\title{
Posters: Systems Biology
}

\section{Analysis of the barley proteome during the early germination}

\author{
Birgit C. Bønsager, Christine Finnie, and Birte Svensson \\ Biochemistry and Nutrition Group, BioCentrum-DTU, Technical University of \\ Denmark, Søltoft Plads, Bldg 224, DK-2800 Kgs. Lyngby, Denmark
}

Germination of barley seeds induces the onset of many cellular processes which provoke severe changes in the proteome pattern of the water soluble proteins in extracts of the whole seed (Østergaard et al., 2004).

2D gel electrophoresis of the water soluble protein of dissected barley seeds during the germination (0-24 hours) and the following radicle elongation (24-72 hours) was carried out for identification of initial changes in the protein profile by mass spectrometry. The study of the individual tissues of the seed (embryo, aleurone layer and endosperm) enriched the less abundant proteins and enabled assignment of certain proteins to the function of the specific tissue (Finnie and Svensson, 2003). The first changes in the barley proteome were observed in the embryo protein pattern at four hours after imbibition. This was followed by a drastic decrease in abundance of several proteins suggested to be involved in desiccation tolerance. Full length form of other desiccation stress related protein (aldose reductase and glyoxalase I) decreased in abundance and were replaced by different patterns of fragments in the three tissues. Oxidative stress related proteins either remained constant (superoxide dismutase, glutathione $S$ transferase, glutathione reductase) or decreased (peroxiredoxin, thioredoxin $\mathrm{h}$, GSH-dependent dehydroascorbate reductase I) during the radicle elongation. Ascorbate peroxidase, however, appeared only in the embryo proteome pattern after 36 hours supporting the hypothesis that the ascorbate system is not involved in desiccation tolerance.

Finnie, C. and Svensson, B. (2003) Feasibility study of a tissue-specific approach to barley proteome analysis: aleurone, endosperm, embryo and single seeds. J. Cereal Science 38, 217-227.

Østergaard, O., Finnie, C., Laugesen, S., Roeostorff, P., Svensson, B. (2004) Proteome analysis of barley seeds: Identification of major protein from twodimensional gels (pl 4-7). Proteomics 4, 2437-2447. 


\section{Posters: Systems Biology}

\section{Characterisation of Vacuolar-specific Proteins from Potato Tuber}

Malene Jørgensen and Karen G. Welinder,

Department of Life Sciences, Aalborg University, Sohngaardsholmsvej 49, DK9000 Aalborg, Denmark, mi@bio.auc.dk

Plant cells contain two functionally distinct vacuoles, a lytic vacuole and a protein-storage vacuole (PSV). An essential scientific question relates to the signals or signatures (tags) of the proteins for their proper sorting to the different types of vacuoles. Signals are often cut off on import to an organelle. Knowledge of the signals will be obtained by comparing the MS determined amino acid sequences of the mature vacuolar proteins with the corresponding translated cDNA sequences previously derived by EST sequencing (Crookshanks et al. 2001, FEBS Lett. 506, 123-126).

Intact vacuoles from field grown potato tuber (Solanum tuberosum cv. Kuras) have been isolated. The technique employs a cutting device that disrupts plant cells without disrupting the organelles due to the short time of exposure to shear forces (5-10 s). After this tissue homogenization the vacuoles are separated from other cell components and concentrated by differential and density gradient centrifugation techniques. The vacuoles are readily identified by bright-field microscopy by their large size and staining with neutral red. The preparations are assessed for intactness, cytosolic and mitochondrial contamination by appropriate enzyme assays.

The proteins of the vacuole-enriched fraction were separated by gelfiltration on a Superdex 200 column. The protein pattern was compared with the gelfiltration profile and SDS-gel pattern of a protein extraction of the intact potato tubers. Several proteins were enriched in the vacuole fraction, especially patatin and protease inhibitors. The proteins from the gelfiltration will be identified by Peptide Mass Fingerprint and sequenced by nano-LC MS/MS analysis of derived tryptic peptides for further analysis and identification of the signal peptide guiding to the vacuoles. 


\section{Posters: Systems Biology}

\section{Proteomics of Legume Seed Development}

Brian S. Laursen ${ }^{1}$, Svend Dam ${ }^{1}$, Astrid L. Lassen ${ }^{1}$, Jane H. Ørnfelt ${ }^{1}$, Bjarne Jochimsen ${ }^{1}$, Ida Thøgersen ${ }^{1}$, Jan J. Enghild ${ }^{1}$, Peter Roepstorff ${ }^{2}$ and Jens Stougaard ${ }^{1}$

${ }^{1}$ Department of Molecular Biology, University of Aarhus, Gustav Wieds vej 10c, DK-8000 Århus, Denmark.

2 Department of Biochemistry and Molecular Biology, University of Southern Denmark, Campusvej 55, DK-5230 Odense M, Denmark.

Legume seeds are an important part of human and animal diets. However, legumes are deficient in sulphur-containing amino acids and could be improved for the content of certain essential minerals. Legume seed development proceeds through three phases: 1) cell division / prestorage, 2) Maturation / seed filling and 3) Desiccation. During the first phase the embryo mainly grows by cell divisions, while the growth in the second phase is dominated by cell expansions. The storage compounds (protein, oil and carbohydrates) accumulate during the maturation / seed filling phase. In the desiccation phase the seeds acquire desiccation tolerance and enter a dormant state.

With the final aim of improving the nutritional value of legumes, we isolated seeds and seed pods from 13 stages during development of Lotus japonicus. Proteins were extracted from all stages and separated using SDS-PAGE. Based on the protein pattern in 1D gels and toluidine blue stained slices of the seeds, five stages representing important developmental steps were chosen for further analysis by 2D gel electrophoresis. We estimate a number of 1000-1200 distinct spots pr gel on 2D gels with isoelectric focusing in the range $\mathrm{pH} \mathrm{4-7}$ and 6-11. So far, we have identified nearly 200 of these. Quantification and identification of the protein spots is a work in progress.

We further analysed seed proteins by a GeLC-MS/MS approach. Based on approximately 8000 tandem MS spectra from two developmental stages our preliminary analysis of the data indicate identifications of approximately 700 and 200 proteins from seeds in the maturation / seed filling phase and from mature seeds respectively. 


\section{Posters: Systems Biology}

\section{Novel Functional genomics approach for identification of plant transporter function in Xenopus oocytes}

Hussam H. Nour-Eldin ${ }^{1}$, Morten H. H. Nørholm ${ }^{1}$, Matthias A. Hediger ${ }^{2}$ and Barbara A. Halkier

${ }^{1}$ Plant Biochemistry Laboratory, Center for Molecular Plant Physiology, The Royal Veterinary and

Agricultural University, Thorvaldsensvej 40, DK-1871 Frederiksberg C, Denmark.

${ }^{2}$ Membrane Biology Program and Renal Division, Brigham and Women's Hospital, Harvard

Institutes of Medicine, 77 Avenue Louis Pasteur, MA 02115, Boston, USA.

Plant transporter gene discovery has been based on sequence homology to known transporters or on functional complementation approaches in yeast. These methods are typically limited to identifying transporters of primary metabolites. We report the identification of an Arabidopsis sugar transporter by a functional genomics approach based on Xenopus expression cloning. A normalized library of full-length cDNA Arabidopsis secondary transporters has been constructed covering approximately $70 \%$ of all expressed secondary transporters. In an initial radiolabeled glucose uptake screen the library was expressed in Xenopus oocytes in a column and row setup allowing rapid functional screening of the library. Several novel glucose transporters were identified and are being being biochemically characterized. Currently, the library is being optimized for translation in Xenopus oocytes by incorporating Xenopus B-globin 5' and 3' UTRs up- and downstream of the individual cDNAs, respectively. The optimized library will be ideal for identifying transporters of any substrate of interest. 


\section{List of Paticipants}




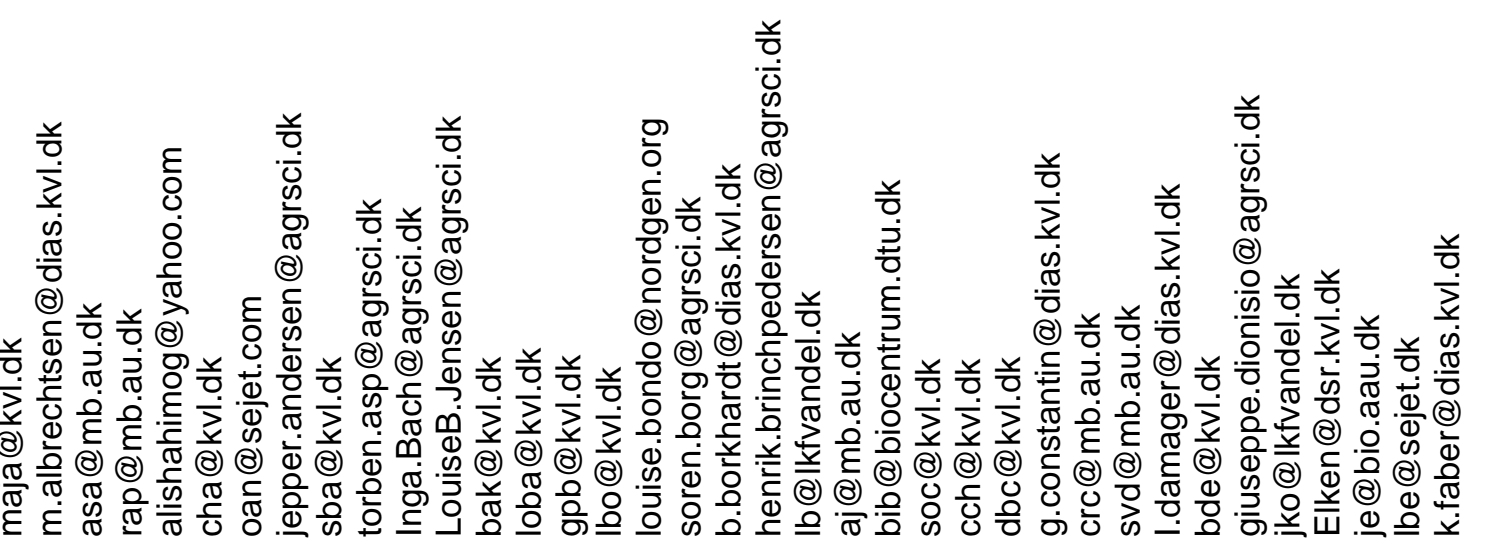

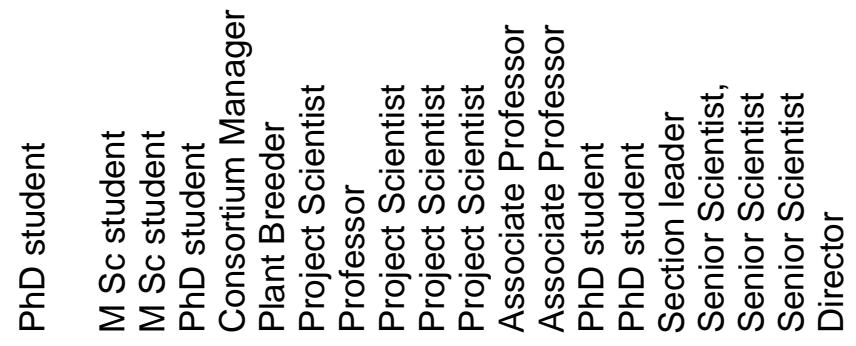

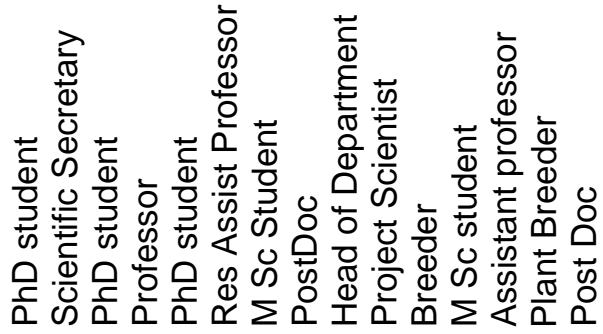

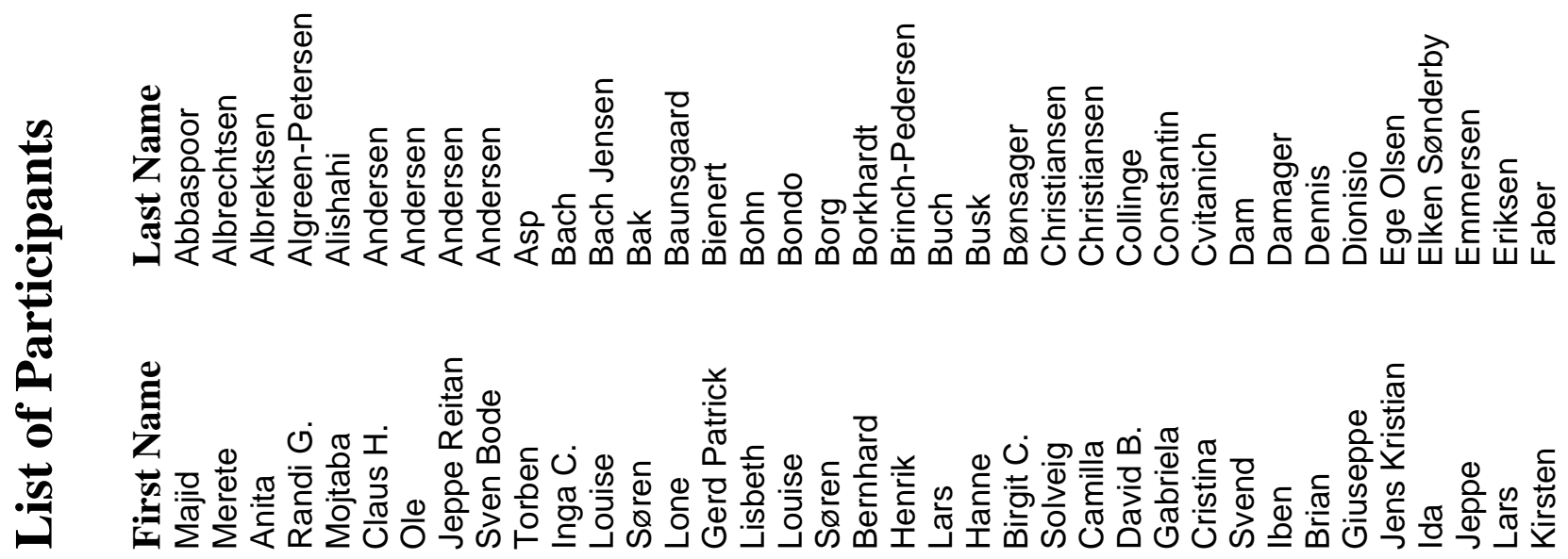


兰

$\dot{\tilde{g}}$

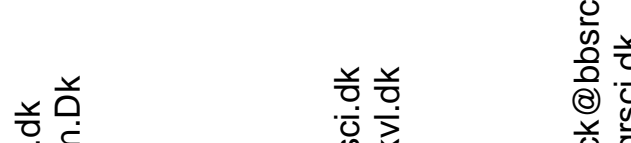

至离

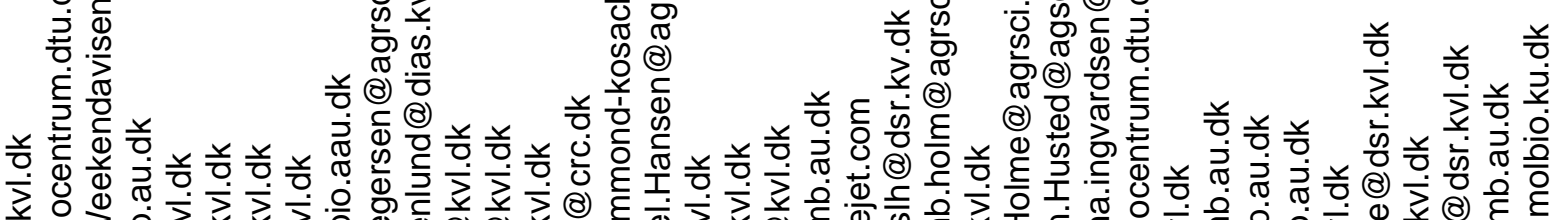

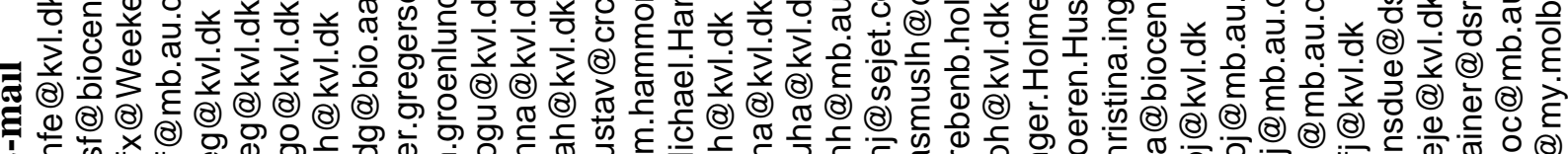

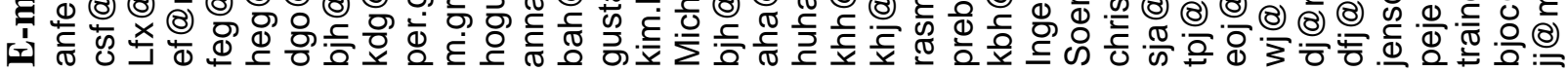
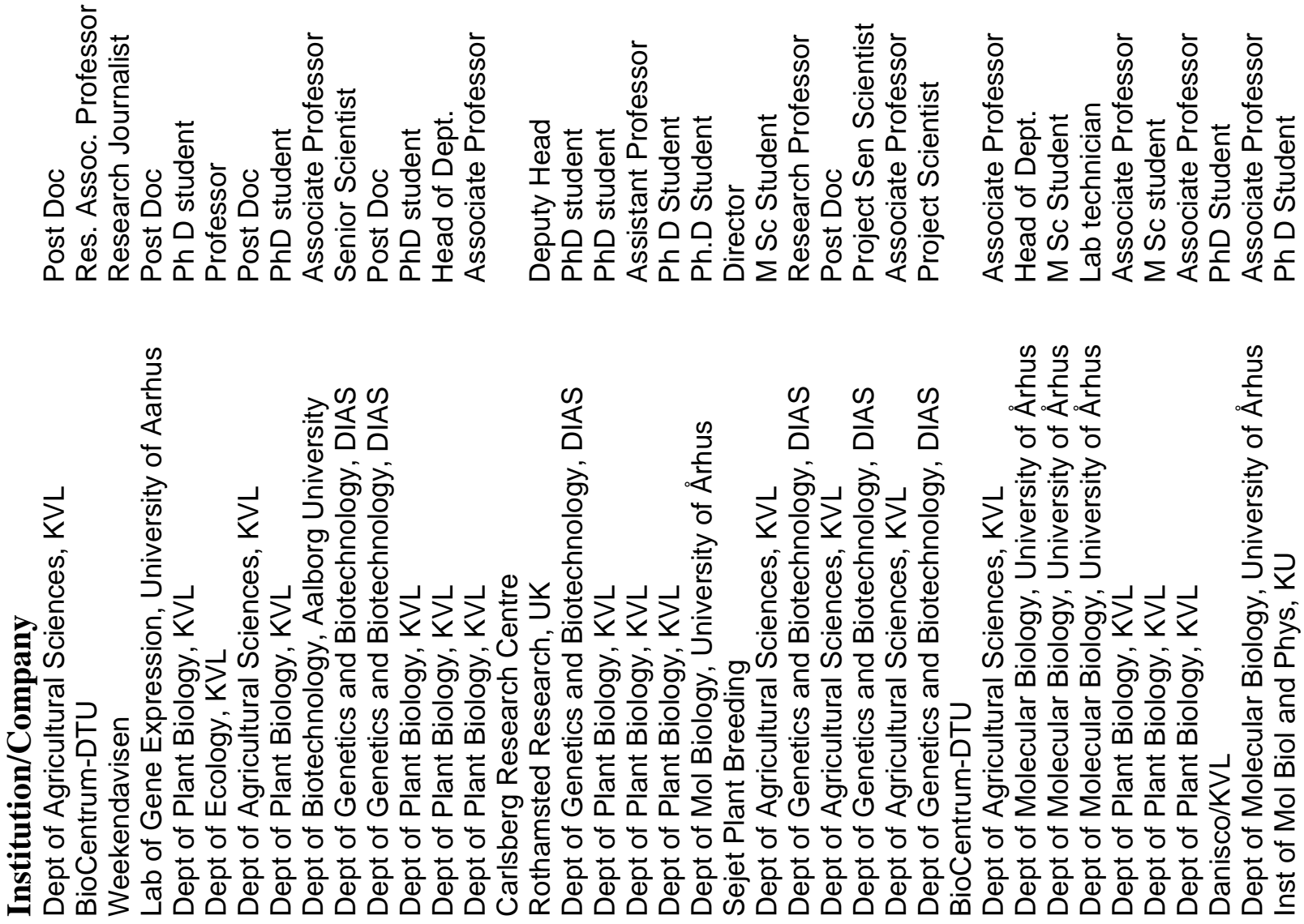

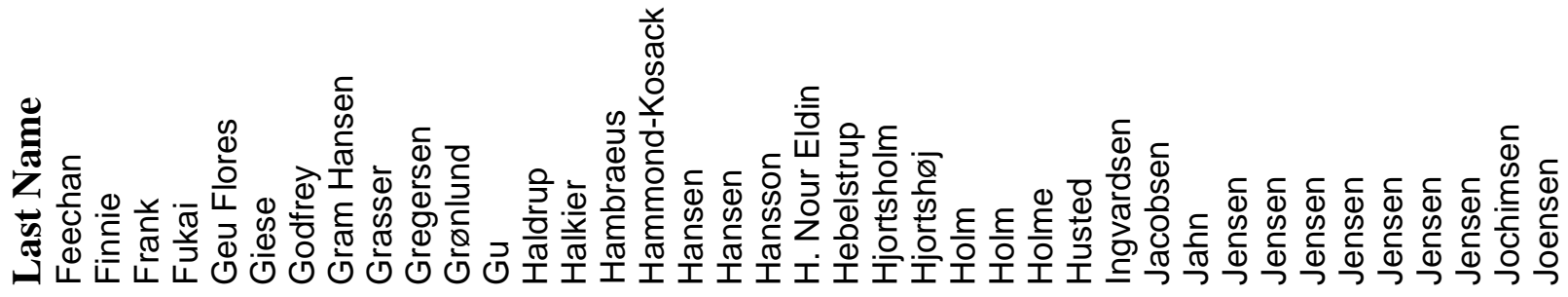

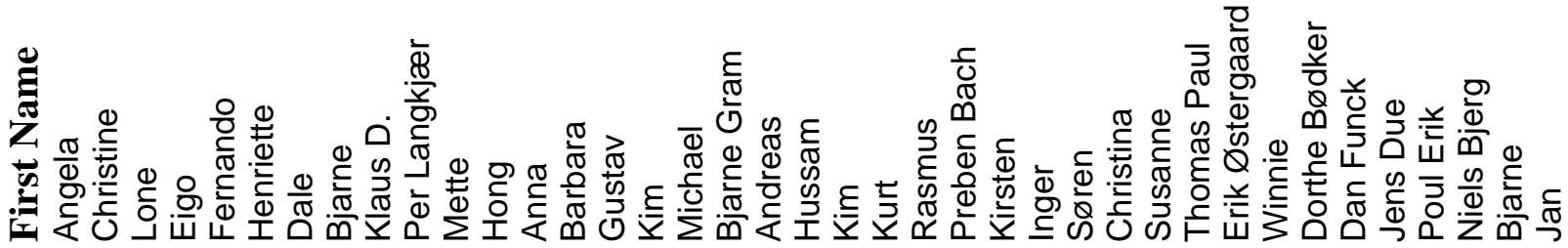




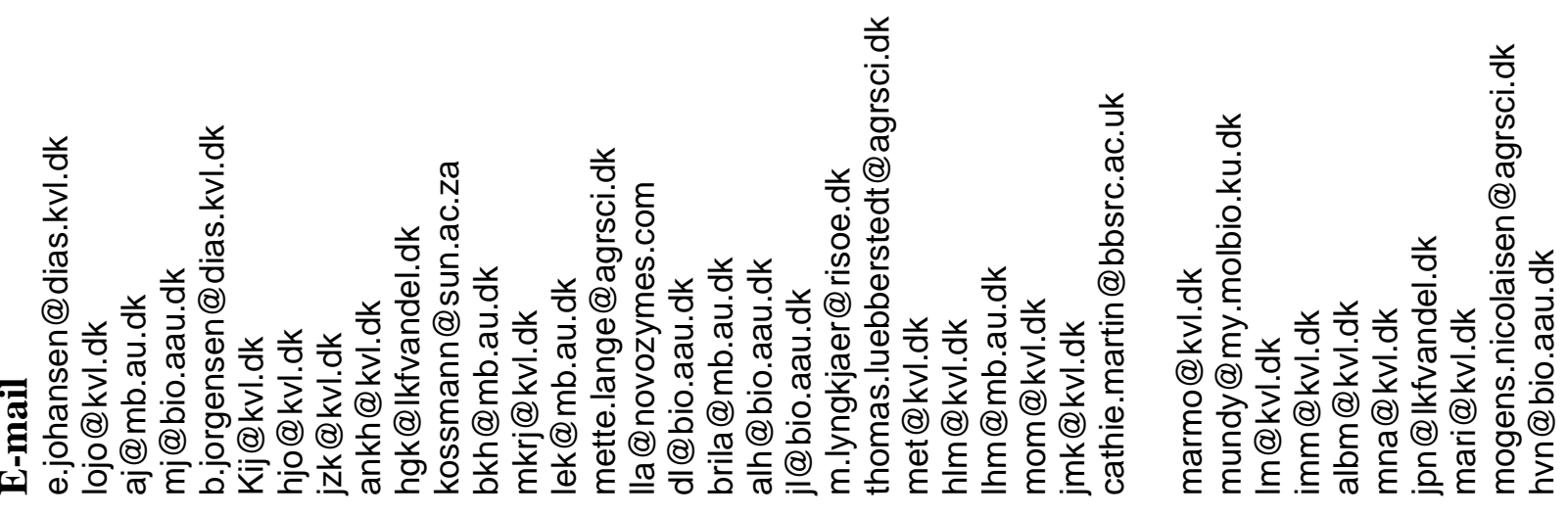

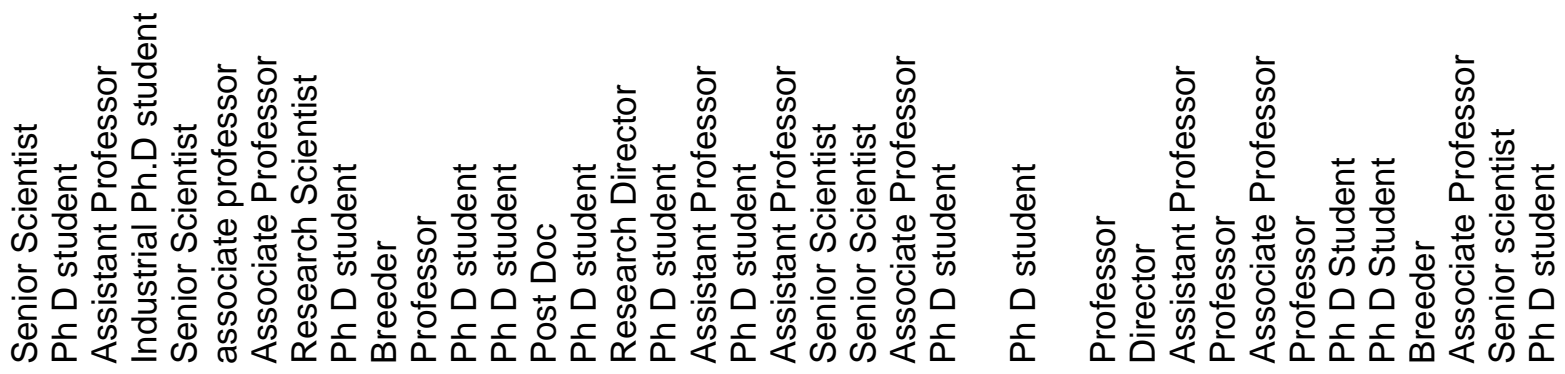

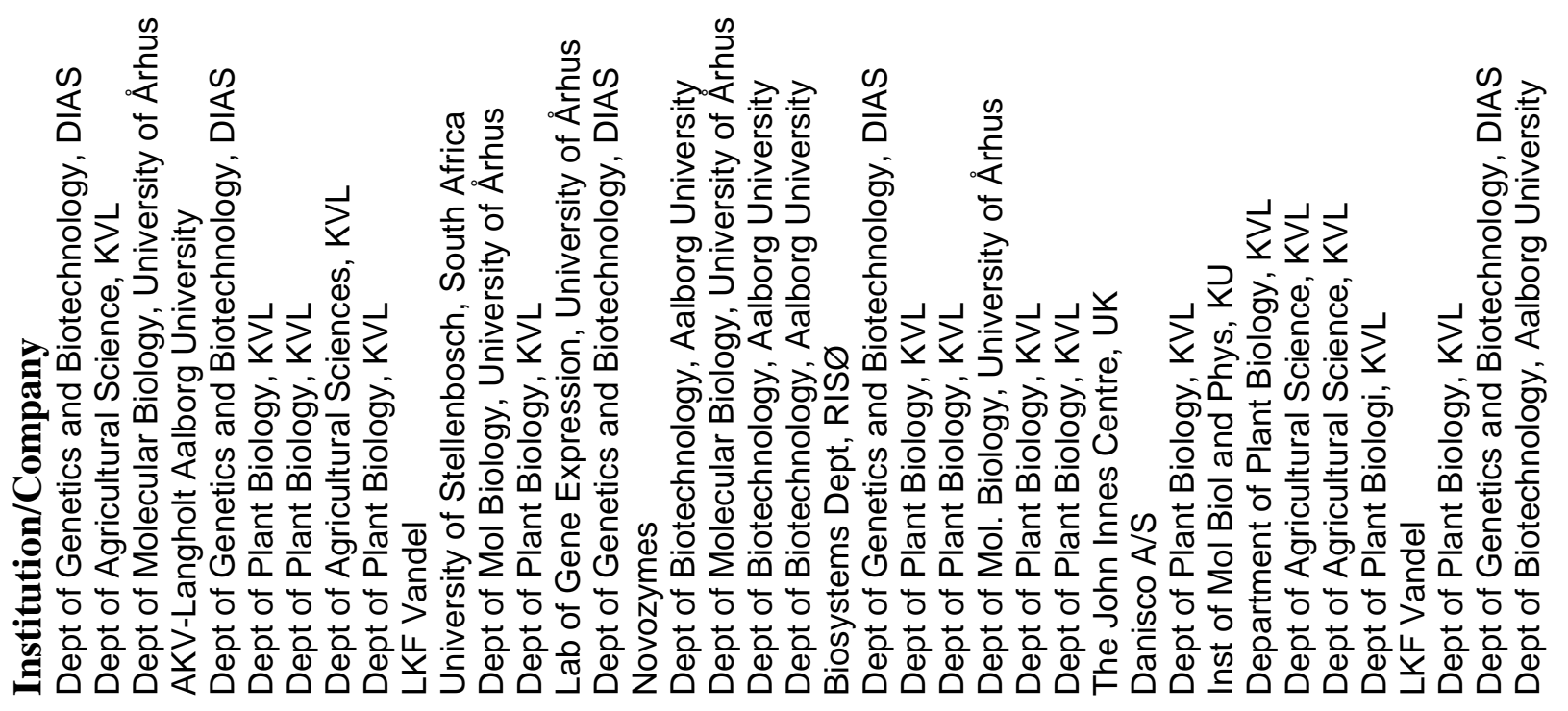

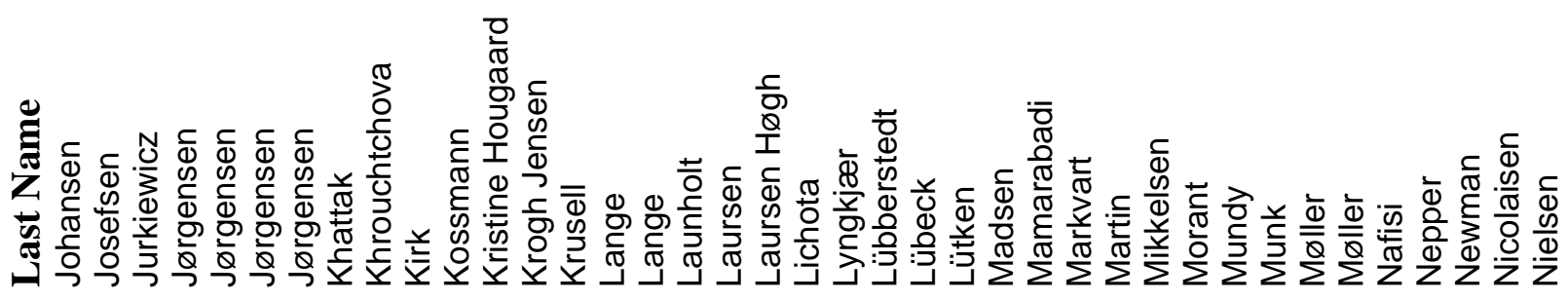

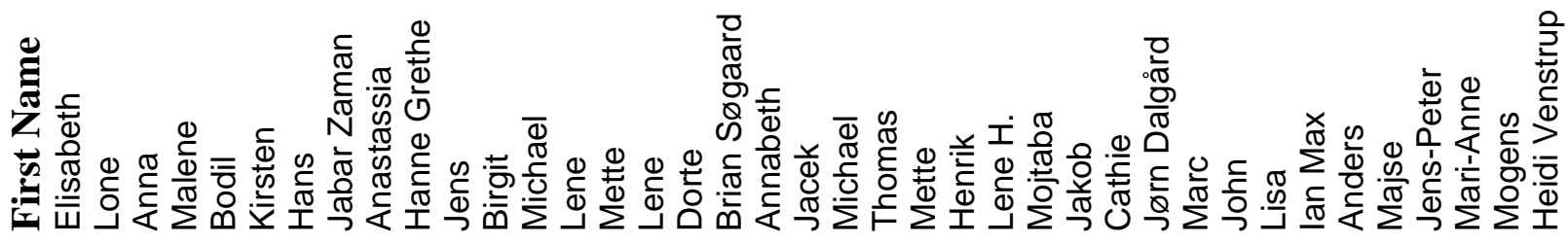



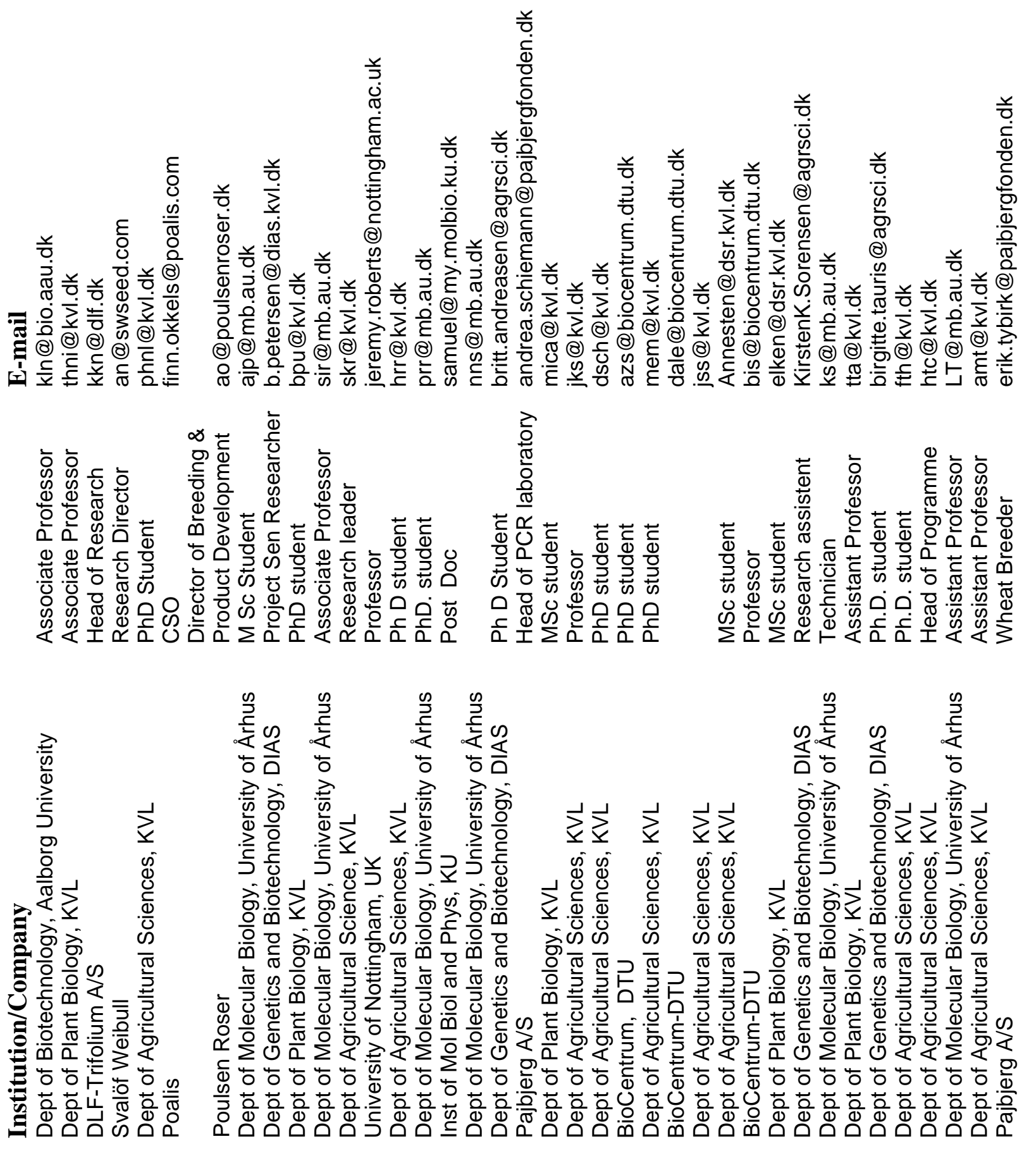

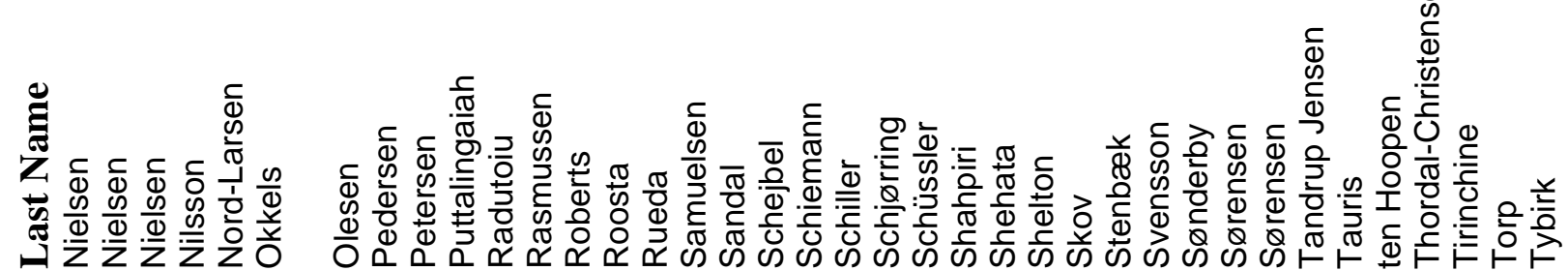

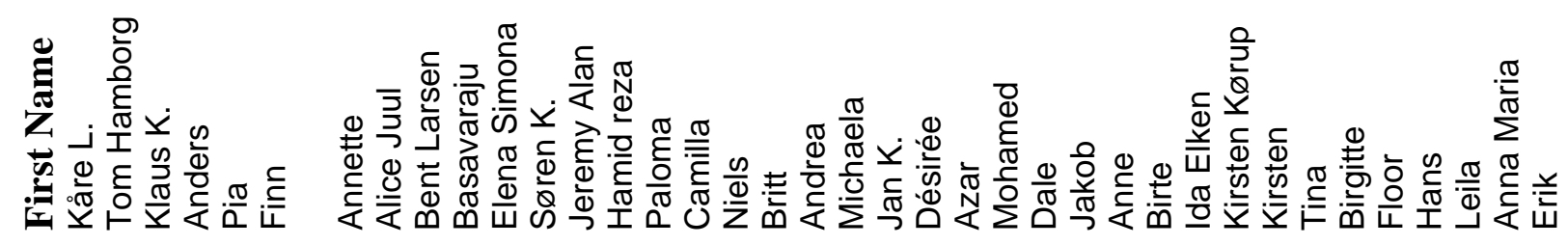



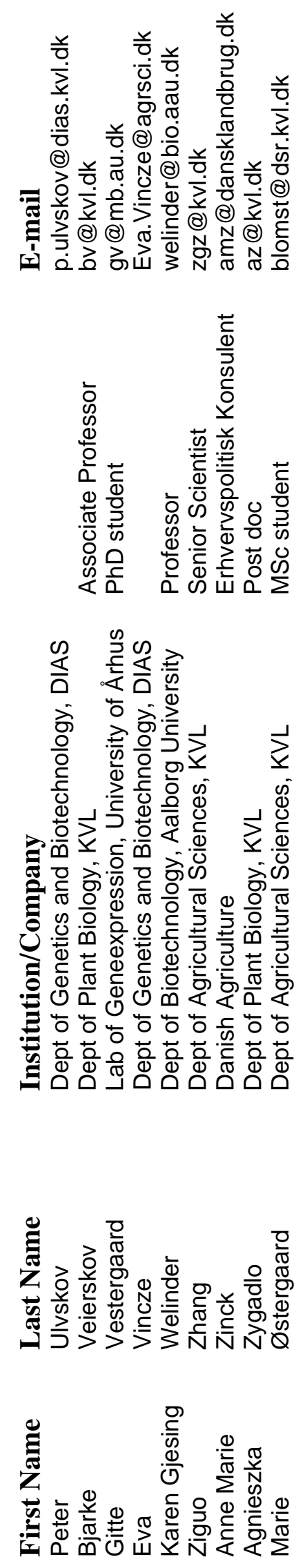
